\title{
A Strategic Vision and a New Management Approach for the Department of the Navy's Research, Development, Test and Evaluation (RDT\&E) Portfolio
}

Joseph P. Lawrence III

Center for Technology and National Security Policy National Defense University

August 2014 


\section{Report Documentation Page}

Form Approved

OMB No. 0704-0188

Public reporting burden for the collection of information is estimated to average 1 hour per response, including the time for reviewing instructions, searching existing data sources, gathering and maintaining the data needed, and completing and reviewing the collection of information. Send comments regarding this burden estimate or any other aspect of this collection of information,

including suggestions for reducing this burden, to Washington Headquarters Services, Directorate for Information Operations and Reports, 1215 Jefferson Davis Highway, Suite 1204, Arlington

VA 22202-4302. Respondents should be aware that notwithstanding any other provision of law, no person shall be subject to a penalty for failing to comply with a collection of information if it

does not display a currently valid OMB control number.

1. REPORT DATE

AUG 2014

2. REPORT TYPE

3. DATES COVERED

00-00-2014 to 00-00-2014

4. TITLE AND SUBTITLE

A Strategic Vision and a New Management Approach for the Department of the Navy's Research, Development, Test and Evaluation (RDT\&E)

Portfolio

6. $\operatorname{AUTHOR}(\mathrm{S})$

7. PERFORMING ORGANIZATION NAME(S) AND ADDRESS(ES)

Center for Technology and National Security Policy,„National Defense

University, ,

9. SPONSORING/MONITORING AGENCY NAME(S) AND ADDRESS(ES)

5a. CONTRACT NUMBER

5b. GRANT NUMBER

5c. PROGRAM ELEMENT NUMBER

5d. PROJECT NUMBER

5e. TASK NUMBER

5f. WORK UNIT NUMBER

8. PERFORMING ORGANIZATION

REPORT NUMBER

10. SPONSOR/MONITOR'S ACRONYM(S)

11. SPONSOR/MONITOR'S REPORT

NUMBER(S)

12. DISTRIBUTION/AVAILABILITY STATEMENT

Approved for public release; distribution unlimited

13. SUPPLEMENTARY NOTES

14. ABSTRACT

15. SUBJECT TERMS

16. SECURITY CLASSIFICATION OF:

a. REPORT

b. ABSTRACT

unclassified

unclassified

c. THIS PAGE

unclassified
17. LIMITATION OF ABSTRACT

Same as

Report (SAR)
18. NUMBER

OF PAGES

66 19a. NAME OF

RESPONSIBLE PERSON 
Disclaimer: The views expressed in this paper are those of the author and do not reflect the official position of the National Defense University, the Department of Defense, or the U.S. Government. All information and sources in this paper were drawn from unclassified materials.

Joseph P. Lawrence III served first as Associate Technical Director and then as Director of Transition at the Office of Naval Research from 2005 to 2011. From 2012, he has held joint appointments as a Senior Research Associate at the Pennsylvania State University's Applied Research Laboratory and, via the Intergovermental Personnel Act (IPA), as a Distinguished Research Fellow at the National Defense University. 


\section{Contents}

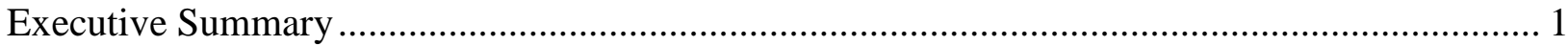

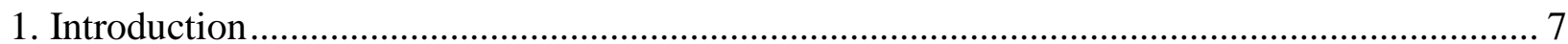

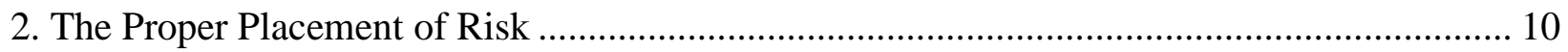

3. Establishment of Strategic Oversight.......................................................................... 14

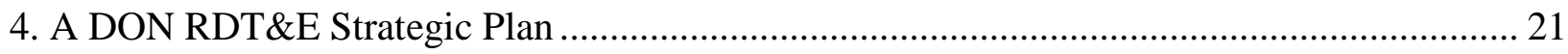

5. RDT\&E Management Implementation............................................................................. 28

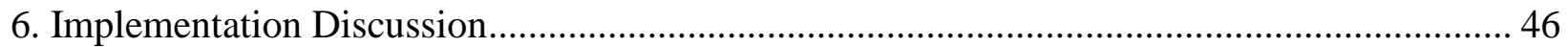

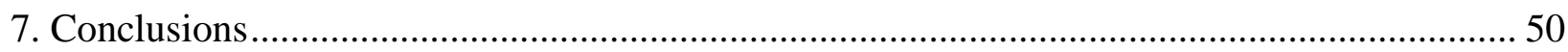

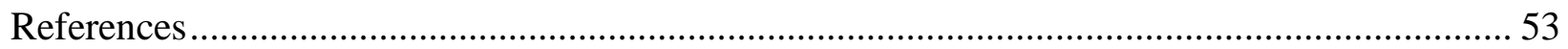

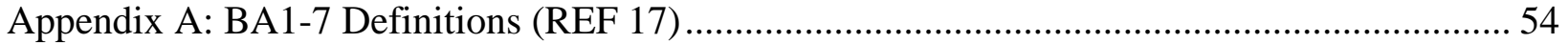

Appendix B: Technology Readiness Levels (TRL) …....................................................... 56

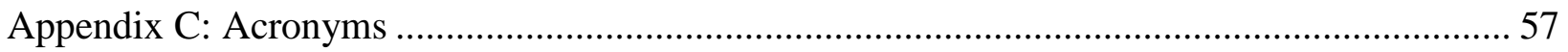

Appendix D: Charter for the Naval RDT\&E Corporate Board ............................................... 60 


\section{Executive Summary}

BACKGROUND. The U.S. Armed Forces are the most capable and dominant military forces in the world. As forces shrink, however, that capability and dominance has been and is becoming increasingly dependent on the technological superiority of our forces. The maintenance of that technological superiority comes at a significant cost. The continued wide dissemination and availability of advanced symmetric and asymmetric weaponry to nations and to groups, increased instability particularly in the equatorial regions, the emergence over the last decade or so of a technologically-capable near-peer competitor (both militarily and commercially), and the stresses introduced by a severely declining domestic budget has presented the U.S. military with a demand signal to increase capability. At the same time, funding required to do so has been reduced critically. Budget cutting will continue and likely worsen. There is every indication that the need will continue to increase. The Department of Defense (DOD) is facing a severe crisis, but one that should be addressed also as an opportunity. The U.S. military is clearly being asked to do more with less, but if more is to be done with less, then there needs to be very careful consideration given to making fundamental institutional changes, in particular ones that address the critical arena of resource management. If change is resisted, or if the changes are not done well, the U.S. military could easily end up doing worse with less. Simply put, if things are to stay the same, some things are going to have to change.

This latter theme was underlined by the Secretary of Defense at a late October 2013 stand-up at the Pentagon where he articulated six priorities for the Department of Defense:

1. Institutional Reform - As it relates to the sequestration marks DOD will absorb over the next 10 years

2. Developing the Proper Force Construct - As we disengage from Iraq and Afghanistan and address new fiscal realities

3. Managing Readiness

4. Capturing Emerging Capabilities - Specifically space; cyber; intelligence, surveillance, and radar (ISR); and Special Operations Forces (SOF)

5. Achieving Balance

6. Arresting and Managing the Growth in Health Care Costs

The Secretary's first priority alone well defines a major motivation for this paper. It is a demand that the DOD re-form itself and its processes, as critically needed to succeed in a challenging fiscal and geopolitical environment. This paper addresses the Department of the Navy's (DON) Research, Development, Test, and Evaluation (RDT\&E) portfolio as a piece of the overall DOD institution that will be subject to the fiscal crisis and to the increasing demand for new capabilities that address the evolving and growing threats. The paper provides recommendations that address Secretary of Defense priorities 1, 2, and 4:

1. Institutional Reform - Fundamental re-forming of the DON RDT\&E portfolio with:

a) A Strategic Plan developed by senior leadership with program decisions for major parts of the technology development portfolio (i.e., the BA-3 FNC and BA-4) at the senior leadership rather than warfighter-community level; 
b) Early operational demonstrations of new technology-driven capabilities to get warfighter buy-in on requirements, specifications, and capabilities before initiation of a major product development (e.g., Major Development Acquisition Program [MDAP]);

c) Use of early experiments and demonstrations managed by the Systems Commands (SYSCOM), and executed by the Warfare Centers/Labs as Government integration agents, to resolve technology risks, prior to initiation of product development, reducing cost and schedule overruns; and

d) Use of early prototypes as a mechanism for achieving speed to fleet/force.

2. Developing the Proper Force Construct - Re-forming of RDT\&E to be more responsive to senior leadership strategic direction and with specific program prioritization and approval by senior leadership to drive the RDT\&E pipeline to deliver technology-enabled capabilities that align with leadership's vision for the proper force construct, and to do so with early feedback to leadership from the fleet and force enabled by early prototype demonstrations.

4. Capture Emerging Capabilities - Developing a robust RDT\&E plan with incentives for risk taking in technology development (and particularly in science and technology [S\&T]) and with provision for early operational demonstrations to promote S\&T development of and fleet/force early buy-in on innovative technologies.

OBSERVATION. The fundamental goal of the DON RDT\&E program is to identify, develop, and maintain the capabilities of our Naval warfighters as notably the most advanced in the world. In this paper, the RDT\&E program is considered holistically. An underlying premise, inclusive of the budget crisis but that both preceded and now transcends the budget crisis, is that DON is not doing a good enough job of strategically managing its RDT\&E portfolio and that, at least partly as a result, DON is spending too much and taking too long in getting new technologydriven capabilities into the hands of our warfighters. Institutional reform is needed. Some specific observations are:

1. DON effectively encourages risk in acquisition programs by allowing them to initiate with unproven technologies and with uncertain requirements and effectively discourages risk in S\&T programs by demanding a high S\&T transition success rate.

2. DON executes RDT\&E at the tactical, not strategic, level. There is no unified, strategic Naval RDT\&E Plan vetted and approved by senior leadership.

3. Individual program executive officers (PEO)/program managers (PM) execute research and development (R\&D) at the program level for cost, schedule, and performance, and their resource sponsors manage to budgetary and program wholeness; this is good tactical management, but is not the same as good strategic management.

4. Few prototypes are developed for early field demonstration and even fewer for limited, early, deployed usage by the warfighter.

5. At least partly as a result, acquisition programs too often are initiated with immature requirements/specifications (REF 1) with resultant schedule and cost issues, or worse are completed either failing to meet needs or (at high cost) over-delivering on those needs. 
6. Furthermore, DON has not been following DOD and DON policies in providing oversight of the entirety of the RDT\&E portfolio (REFs 2, 3).

In short, R\&D has become too prototype averse, and S\&T has become too risk averse. This paper will discuss why this state is nearly the opposite from where DON should be operating. This current state is symptomatic of not having a strategic plan. Process, and perhaps more importantly, cultural change is needed.

To address the problems underlying the above observations, the length and breadth of the RDT\&E process will be considered. The paper will examine Strategic Planning through the Technology Explore (Budget Activity [BA] -1 and BA-2), Develop (BA-3), and Transition (BA4) phases; and to the Product Development (BA-5 and BA-7) phase from which emerges weapons and systems that enable advanced capabilities for our fleet and force. Most of the paper's focus will be on the technology development phases of RDT\&E (i.e., BAs 1-4) and will critically explore why these phases need to be preceded by careful Strategic Planning, and followed by a coordinated but very distinctly separate Product Development phase (i.e., BAs 5\&7).

Many studies have been conducted looking at industry and Federal Government RDT\&E practices in transitioning technology from the lab to a product line and then on to customers. For example, the Naval Research Advisory Committee (NRAC) conducted a recent review with primary focus on DON Budget Activity 4 (BA-4) accounts (REF 5). The Government Accountability Office (GAO) conducted a more thorough evaluation (REF 1), earlier, looking at the breadth of DOD RDT\&E practices and comparing them with those of a number of successful technology companies. The Business Executives for National Security (BENS) also conducted a thorough evaluation (REF 6) of DOD acquisition practices using extensive data from defense industry sources. These reports, and others, identified the current lack of and the need for overall strategic planning as a precursor to successful and cost-efficient introduction of new technology to the warfighter. The GAO report, in particular, identified a general flow process that summarized the technology transition and insertion process for the number of leading technology companies that they surveyed. Figure ES1 illustrates this process flow, with the addition of DON BAs as associated with each stage.

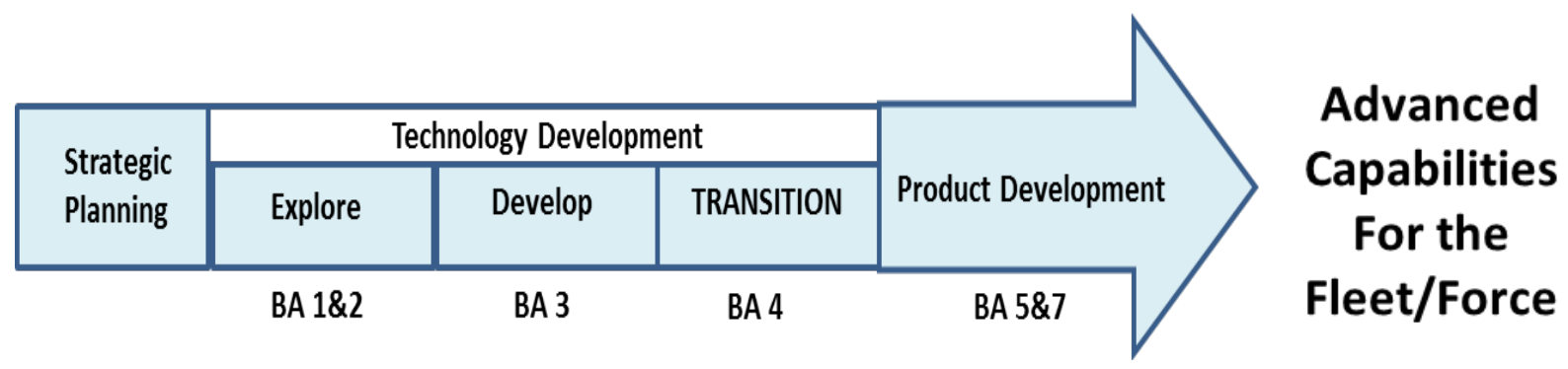

Figure ES1: Process Flow for Technology Insertion

For each of the leading companies evaluated, a similar paradigm was found:

- Corporate management established strategic plans at least annually, enabling portfolio analysis and ensuring that projects remained matched to market needs;

- R\&D activities were organized into "thrusts" (or focus areas) that mapped into the core markets of their businesses; 
- Technology development was kept separate from product development; and

- Early technology development (Explore and Develop) was protected at the corporate level.

The two bolded and underlined aspects of this paradigm are the central topics of this paper. They will be explored and specific recommendations will be made, on the establishment of a corporate strategic plan for RDT\&E and then on the separation of technology development from product development and on the management process necessary to implement the separation.

As we enter into a period where fiscal constraints become ever more severe, DON decision makers, and specifically within the RDT\&E program, will need to make difficult choices that will shape the future of our fleet and force. The ongoing defense budget shrinkage will force significant changes, possibly with severe across-the-board cuts to many program lines, and likely with at least a few major programs being terminated. Rather than doing this cutting "fairly" across the various DON communities (i.e., a "peanut-butter" spread), the argument is made that there is need now for development of a Naval RDT\&E Strategic Plan, based on a consensus from within very senior leadership, to define DON's vision forward. In addition, it is argued that the way forward should include a specific process for senior leadership to define and prioritize the RDT\&E efforts leading to the provision to the fleet and force of those future platforms, weapons, and capabilities that they envision.

The goal of this paper is to identify a workable RDT\&E process that better enables DON to identify, develop, and maintain the capabilities of our warfighters as the most advanced in the world. This position will become increasingly difficult to maintain for many reasons, including increasing budgetary constraints. The approach that will be recommended is intended to:

1. Promote faster and more cost efficient acquisition development by resolving requirements early and by discouraging technology risk-taking in our acquisition community,

2. Speed technology insertion into the fleet/force with early prototype deliveries as an integral part of the development process, and

3. Engender greater payoff from our S\&T by encouraging focused risk-taking by our science and engineering (S\&E) community.

Notably, the proposed approach will identify and provide a viable bridge within and across the RDT\&E communities that includes critical operational feedback from the fleet/force enabling needed new technology-based capabilities to be identified, experimented and demonstrated, vetted and then acquired efficiently and with minimal residual operational risks. Moreover, with warfighter vetting of new capabilities via early prototype field experimentation, the acquired capability demonstrably will be what the warfighter wants and needs. Provision also will be made for rapid fielding of select critical capabilities, well in advance of final delivery by a formal acquisition program of record (POR).

RECOMMENDATIONS. It is worth repeating the conclusion from several of the cited studies that (REF 7) "simultaneously developing new technology within an acquisition program is a recipe for disaster." GAO (REF 1) strongly recommended (a) that technology development and product development be managed separately, and (b) that DOD not initiate a POR until the 
technology value and maturity have been verified in operational demonstrations. BENS (REF 6) and the Under Secretary of Defense for Acquisition, Technology, and Logistics (AT\&L) (REF 8) both cited immature technologies and unsteady specifications/requirements as major causes for POR schedule slippage and cost overruns. The BENS study went on to recommend that DOD technology development (i.e., BAs 1-4) should embrace a higher risk level at the same time that PORs (i.e., BAs 5 and 7) follow a significantly lower risk approach. While the USD AT\&L notes that over the period from 1997-2011 31 percent of all DOD MDAPs had Nunn-McCurdy breaches, it is worth noting from S\&T that less than 10 percent of BA-3 Future Naval Capability projects were judged by Navy Headquarters Staff (OPNAV) and Marine Corps Headquarters Staff (HQMC) reviewers as having failed. A major assertion in this paper is that this is backwards, that is, that the DOD should have a very high success rate for MDAPs, with infrequent severe cost growth and/or severe schedule slippage, and that S\&T should seek breakthrough capabilities, with resultant higher failure rates, but with the expectation that those S\&T programs that do succeed will have more noticeable impact and value.

Eight specific recommendations are made and discussed in the paper. The first three recommendations represent the core of the paper, with the balance of the recommendations providing support and implementation approaches underneath the first three.

Recommendation 1: Discourage acquisition category (ACAT) program risk taking by requiring an initial technology readiness assessment (TRA) to show all critical technology elements (CTE) to be at technology readiness level (TRL) 7 or higher. Encourage greater risk taking in S\&T transitioning programs, and in general stop S\&T development at a TRL 6. (See Appendix B for TRL Definitions.)

Recommendation 2: Manage the DON BA4 program strategically, and as a distinct portfolio, to achieve DON speed-to-fleet goals, address risk reduction for new technologies prior to inclusion in PORs, gain warfighter buy-in of new capabilities via operational experimentation, refine requirements prior to initiation of a POR or a mod to a POR; and do so separate from product development (BAs 5 and 7) program management.

Recommendation 3: Establish a DON RDT\&E Corporate Board with the charter to provide strategic oversight, establishment of prioritization, and management of the DON RDT\&E portfolio, and require the Board biennially to develop and publish a DON RDT\&E Strategic Plan.

The promulgation by the Secretary of the Navy of a Charter for the DON RDT\&E Corporate Board is acknowledged. The recommendations provided in the paper, however, go beyond the responsibilities and authorities provided for in that Charter, and if adopted, warrant a revision to the Charter. The recommendations also will result in the called-for Naval RDT\&E Strategic Plan to be considerably different in scope, laying out direction for the future as well as providing a new process for prioritization, selection, and execution management of BA-4 projects and providing a senior-leadership-committed balance of investments across the RDT\&E portfolio to meet the current and future needs of the Naval services. The remaining five recommendations address some of the issues in full implementation of the first three recommendations.

Recommendation 4: The DON RDT\&E Strategic Plan should identify the leadership vision for future directions of the Naval services, defining specific 
processes for selection, initiation and management of those future directions, and laying out a balanced investment plan allotting RDT\&E funds to address mid- and long-term investment needs.

Recommendation 5: The RDT\&E Corporate Board should assign management of and proposal development for the DON BA-4 portfolio to the DON Systems Commands, with execution through a Naval Lab or Warfare Center, and with intermediate management oversight by a 3-star Technology Oversight Board (TOB) with a 2-star integrated product team (IPT) support structure based on the thrust areas defined within the RDT\&E Strategic Plan.

This recommended structure provides for a clear separation of product development from technology development. It is a critical recommendation that also provides for clear senior level management oversight of the DON BA-4 portfolio.

Recommendation 6: The RDT\&E Corporate Board, through the TOB, should track success or failure of completing BA-4 and BA-3 FNC projects based on IPT assessments and should track completed projects through to final product delivery using an independent, appointed, Technology Review Board (TRB).

Recommendation 7: Within the RDT\&E Strategic Plan, explicitly recognize the BA-4 Portfolio as consisting of (a) Speed to Fleet/Force; (b) SYSCOM Seams and BA-4 Jump-Start; (c) Proof of Value, including specifically a significant Innovations investment; (d) Requirements Refinement; and (e) Technology Risk reduction. Identification should be made of minimum budgeting goals for each category.

Recommendation 8: The RDT\&E Corporate Board, through the TOB and subordinate IPTs, should conduct an annual or biennial review and critical assessment of all ongoing and proposed new BA-5 and BA -7 programs.

CONCLUSIONS. DOD is in the midst of a severe budget crisis, made worse by the likely continuation of sequestration. The Secretary of Defense has recognized that the only logical path to the future includes institutional change. This paper recognizes this crisis and prior underlying problems, and for at least the RDT\&E portfolio, recommends a significant change that includes a re-forming of the DON RDT\&E portfolio, with a Strategic Plan developed by senior leadership; program decisions for major parts of the technology development portfolio (i.e., the BA-3 Future Naval Capability [FNC] and BA-4) at the senior leadership rather than warfighter-community level; early experimentation and operational demonstrations of new technology-driven capabilities to get warfighter buy-in on requirements, specifications, and capabilities before initiation of an major product development (e.g., MDAP); use of early experiments and/or demonstrations managed by the SYSCOMs to resolve technology risks, prior to initiation of product development, reducing cost and schedule overruns; and use of early-fielded prototypes as a mechanism for achieving speed to fleet/force. The expectation is that adoption of the recommendations will result in a significantly lower risk of cost and schedule growth in DON product development and production programs, broadly achieve S2F/F for critical new technologies, and foster greater innovation in S\&T. 


\section{Introduction}

This paper considers the Department of the Navy (DON) Research, Development, Test, and Evaluation (RDT\&E) program holistically. The underlying premise, that will be expanded on here, is that DON is not doing a good enough job of strategically managing its RDT\&E portfolio and that, at least partly as a result, DON is spending too much and taking too long in getting new technology-driven capabilities into the hands of our warfighters. Some specific observations are that:

1. We effectively encourage risk in our acquisition programs by allowing them to initiate with unproven technologies and with uncertain requirements; and we effectively discourage risk in our science and technology (S\&T) programs by demanding a high S\&T transition success rate.

2. We execute RDT\&E at the tactical, and not strategic, level. There is no unified, strategic Naval RDT\&E Plan vetted and approved by senior leadership.

3. Individual program executive officers (PEO)/program managers (PM) execute research and development (R\&D) at the program level for cost, schedule, and performance, and their resource sponsors manage to budgetary and program wholeness; this is good tactical management, but is not the same as good strategic management.

4. Few prototypes are developed for early field experimentation and even fewer for limited, early, deployed usage by the warfighter.

5. At least partly as a result, acquisition programs too often are initiated with immature requirements/specifications (REF 1) with resultant schedule and cost issues, or worse are completed either failing to meet needs or (at high cost) over-delivering on those needs.

6. The DON has not even been following DOD and DON policies in providing oversight of the entirety of the RDT\&E portfolio (REFs 2, 3).

In short, R\&D has become too prototype averse, and S\&T has become too risk averse. This paper will discuss why this state is nearly opposite from where DON should be operating. This current state is symptomatic of not having a strategic plan. Process, and perhaps more importantly, cultural change is needed.

The goal of this paper then is to identify a workable RDT\&E process that better enables DON to identify, develop, and maintain the capabilities of our warfighters as notably the most advanced in the world. This position will become increasingly difficult to maintain for many reasons, including increasing budgetary constraints. The approach that will be recommended is intended to: (a) promote faster and more cost efficient acquisition development by resolving requirements early and by discouraging technology risk-taking in our acquisition community, (b) speed technology insertion into the fleet/force with early prototype deliveries as an integral part of the development process, and (c) engender greater payoff from our S\&T by encouraging focused risk-taking by our science and engineering (S\&E) community. Notably, the proposed approach will identify and provide a viable bridge within and across the RDT\&E communities that includes critical operational feedback from the fleet/force enabling needed new technology-based capabilities to be identified, experimented and demonstrated, vetted, and then acquired efficiently and with minimal residual operational risks. Moreover, with warfighter vetting of new 
capabilities via early prototype field experimentation, the acquired capability demonstrably will be what the warfighter wants and needs. In addition, provision will be made for rapid fielding of select critical capabilities, well in advance of final delivery by a formal acquisition program of record (POR).

As we enter into a period where fiscal constraints become ever more severe, DON decision makers, and specifically within the RDT\&E program, will need to make difficult choices that will shape the future of our fleet and force. The ongoing defense budget shrinkage will force significant changes, possibly with severe across-the-board cuts to many program lines, and likely with at least a few major programs being terminated. Rather than doing this "fairly" across the various DON communities, now is the time to develop a Naval RDT\&E Strategic Plan, based on a consensus from within senior leadership on a way forward, and including provision for senior leadership to define and regularly review a prioritized listing of RDT\&E efforts that will provide the platforms and weapons systems envisioned by senior leadership as truly needed for our future fleet and force.

To provide some perspective on the DON RDT\&E program, Figure 1 illustrates budgetary data for the various parts of RDT\&E as included in the President's Budget for FY14, PB14. The DON projected a commitment of a significant fraction of the overall DON budget to be used for RDT\&E. The amounts projected are not enough to accomplish all the goals that the Department would like, but clearly should be considered as too much to commit absent a well-reasoned strategic RDT\&E plan. Appendix A provides a definition of each of the constituent parts of RDT\&E.

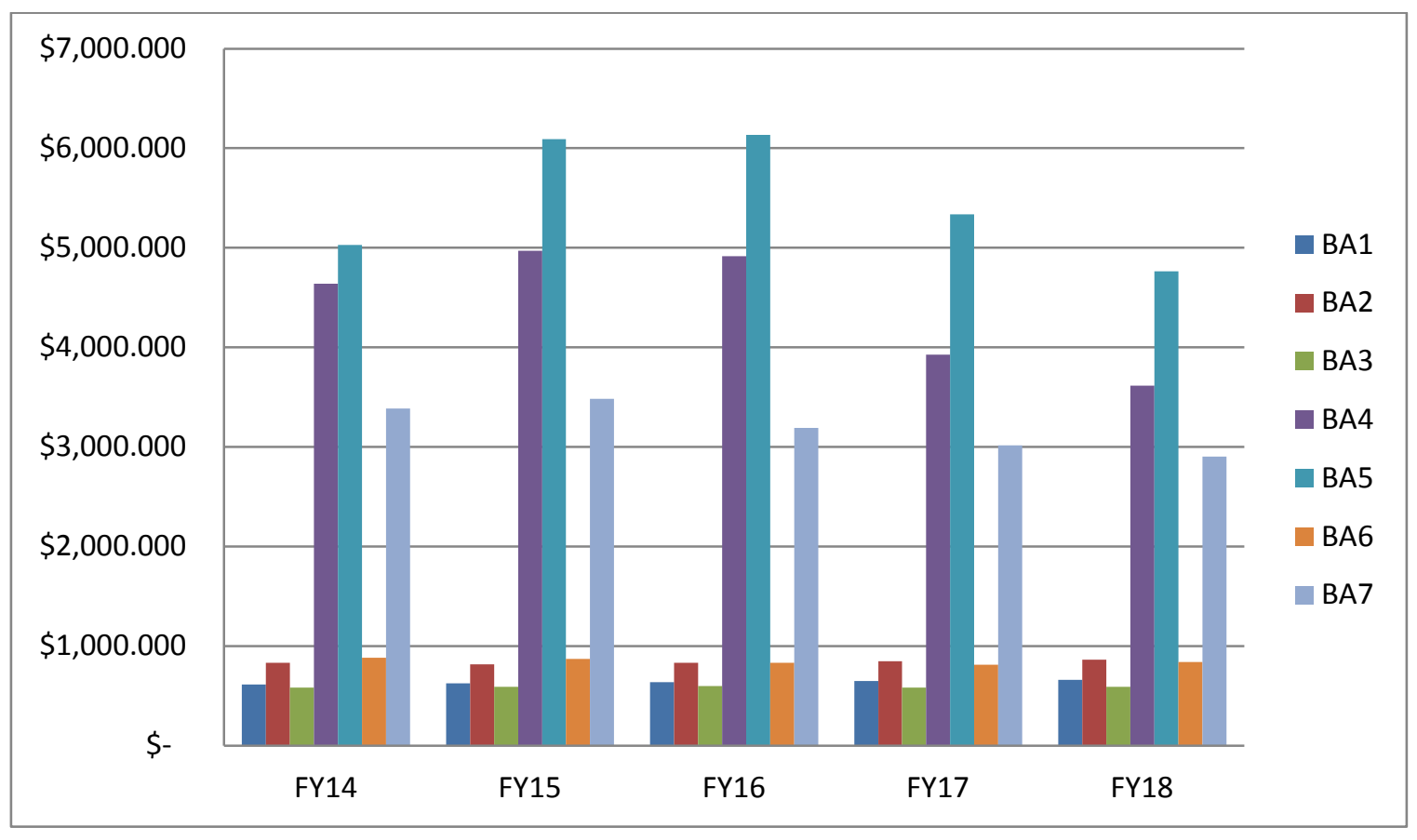

Figure 1: RDT\&E Budget, PB14 (\$millions)

Budget activities (BA) 1-3 are governed by a 4-star approved Strategic Plan, and transitioning S\&T programs are subject to a 3-star review and approval. There is no Strategic Plan for the rest of the RDT\&E portfolio, and arguably there is little to no senior oversight of the BA-4 portfolio. 
It would be hard to disprove the assertion that the DON micromanages the "little" RDT\&E BAs at the 4 and 3 star level, and doesn't manage the big ones anywhere near as much or as well.

In the following sections, we discuss these issues in more detail and provide specific recommendations for addressing them. While the immediate focus here is on DON, the recommendations may have validity as well for the other components within the Department of Defense (DOD).

It is noted that on March 19, 2013, the Secretary of the Navy signed a Charter (REF 16) for a Naval RDT\&E Corporate Board (see also Appendix D: Naval RDT\&E Corporate Board Charter). That Charter gives the RDT\&E Corporate Board the broad responsibility to "establish and maintain a coordinated and comprehensive RDT\&E program to meet Naval goals and objectives." It does so by executing the responsibilities previously given the DON S\&T Corporate Board, plus: (1) providing recommendations on strategic RDT\&E issues and policy changes to the Secretary of the Navy, the Chief of Naval Operations (CNO), and the Commandant of the Marine Corps (CMC); and (2) providing recommendations on strategic investments for Naval RDT\&E, including “oversight on Naval RDT\&E Strategic Plan.” The establishment of this Charter provides a framework upon which a comprehensive Naval RDT\&E Strategy can be implemented. The "execution responsibility" to provide "recommendations" to the Secretary of the Navy, CNO, and CMC, however, can be construed as stopping short of truly empowering the RDT\&E Corporate Board to "establish and maintain a coordinated and comprehensive RDT\&E program.” In the balance of this paper, the author will propose an implementation approach for this Board that does support the establishment and maintenance of a coordinated and comprehensive Naval RDT\&E program.

First, however, it is worth exploring a significant underlying problem within the DON RDT\&E structure. Namely, we effectively encourage risk in our acquisition programs by pushing them to initiate with unproven technologies and with uncertain requirements, and we effectively discourage risk in our S\&T programs by demanding a high S\&T transition success rate. In order to address this problem, a Corporate Board "prime directive" should be to establish the proper placement and balance of risk across the entire RDT\&E portfolio. 


\section{The Proper Placement of Risk}

Many studies have been conducted looking at industry and Federal Government practices in transitioning technology from the lab to a product line and then on to customers. The Naval Research Advisory Committee (NRAC) conducted a recent such review with primary focus on the DON BA4 account (REF 5). The Government Accountability Office (GAO) conducted a more thorough evaluation (REF 1), earlier, looking at the breadth of DOD RDT\&E practices and comparing them with those of a number of successful technology companies. The Business Executives for National Security (BENS) also conducted a thorough evaluation (REF 6) of DOD acquisition practices using extensive data from defense industry sources. These reports, and others, identified the current lack of and the need for overall strategic planning as a precursor to successful introduction of new technology to the warfighter. The GAO report, in particular, identified a general flow process that summarized the technology transition and insertion process for the number of leading technology companies that they surveyed. Figure 2 illustrates this process flow, with the addition of DON BAs as associated with each stage.

\begin{tabular}{|c|c|c|c|c|}
\hline \multirow{2}{*}{$\begin{array}{l}\text { Strategic } \\
\text { Planning }\end{array}$} & \multicolumn{3}{|c|}{ Technology Development } & \multirow{2}{*}{ Product Development } \\
\cline { 2 - 4 } & BA 1\&2 & Develop & TRANSITION & BA 3 \\
& BA 4 & BA 5 \\
\hline
\end{tabular}

Figure 2: Process Flow for Technology Insertion

For each of the leading companies evaluated, a similar paradigm was found:

- Corporate management established strategic plans at least annually, enabling portfolio analysis and ensuring that projects remained matched to market needs;

- R\&D activities were organized into "thrusts" (or focus areas) that mapped into the core markets of their businesses;

- Technology development was kept separate from product development; and

- Early technology development (Explore and Develop) was protected at the corporate level.

The two bolded aspects of this paradigm will be further explored and recommendations made, first in this chapter on the separation of technology development from product development and then in the next two chapters on the establishment of a corporate strategic plan for RDT\&E.

To further explore separation of technology development from product development, it is illuminating to understand what GAO found as constituting each of the stages in technology development, summarized here:

- In the Explore stage, S\&T is evaluated within corporate "thrust" (focus) areas and prospective technologies are identified that have promise for meeting future market needs. Due to the very large a priori uncertainty that is associated with far-reaching new ideas, a high failure rate is expected, and in some ways encouraged, as a multitude of 
new ideas are explored, winnowed, and their feasibility and value for further development is determined. The exit of a technology from the Explore stage requires an initial corporate buy-in on the technology (e.g., Future Naval Capability [FNC] and/or Innovative Naval Prototype [INP] product selection).

- In the Develop stage, laboratory prototypes are developed and evaluated for suitability and for feasibility. Typically, a product line commitment is required during this stage and product line managers begin to be engaged in tracking the technology (e.g., technology transition agreements [TTA] are signed). For the Develop stage, there still are significant risks but much reduced from the level accepted in the Explore stage, and success is clearly anticipated. Nevertheless, a reasonable failure rate is still expected in this stage as operational feasibility, customer valuation, and practicality (including anticipated cost of production and utilization) of the new technology need to be evaluated and assessed.

- In the Transition stage, an operational prototype is developed and evaluated for suitability and manufacturability. Product line managers very closely track the technology to ensure that it readily can be integrated into a product line. The exit from this stage comes with corporate buy-in to hand the now matured technology (technology readiness level [TRL] 7 or higher) to a product line manager who then is responsible for getting the technology to final form, fit, and function prior to initiation of formal production.

In this model from industry, it is only following demonstration of operational feasibility that full responsibility for development of a product then is handed to a product line manager. Notably, this is the opposite of the practice within DON. At DON, the Technology Develop stage (i.e., BA-3 FNCs) is expected to have little to no risk (e.g., greater than a 90-percent success rate as overseen and measured by the Navy Headquarters Staff [OPNAV]/Marine Corps Headquarters Staff [HQMC]-led FNC Technology Oversight Group [TOG]). In addition, the Technology Transition stage (BA-4 activities) efforts are executed within a product development (POR) by the product line (acquisition) community, with no corporate-recognized success metric and no corporate board oversight; and the product development stage is initiated much too often with immature technologies, as recognized in the number of PORs that have formally vetted Technology Readiness Assessment (TRA) reports indicating critical technologies with TRL ratings of 6 , or on rare occasions 5. DON currently is minimizing risk in the S\&T stage, while formally accepting, if not encouraging, risk taking in the product development stage. This is the reverse from industrial good practices and is indicative of the lack of an overall and holistic approach to RDT\&E.

The 2009 report (REF 6) by BENS took a similar approach as that taken by GAO in comparing Defense Department acquisition policies to those utilized within high-tech industries. They developed specific recommendations on:

1. Requirements Determination,

2. The Acquisition Workforce, and

3. Program Execution.

The first and third of the BENS recommendations underscore the conclusions in the above discussion of technology development in high-tech industries (specifically including DOD), and 
are worth summarizing. In Requirements Determination, the BENS authors emphasize the need for an "iterative and interactive" "requirements establishment process" where a strong in-house engineering base within the Services has the "authority to conduct trade-offs and, where appropriate, modify requirements" based in part on an "aggressive but sensible prototyping program" that should be established to "build and test non-production prototypes." In the third recommendation, they note that post-Milestone B efforts should be initiated "only after: (1) the need is firm; (2) the system concept is clear; (3) the necessary funds are likely to be available throughout the proposed effort; and (4) the technology is proven." Again, the emphatic message is that DON should be more willing to accept risk in the S\&T stages (BAs 1-3), but, prior to technology insertion into a POR (BAs 5\&7), DON should resolve residual risks through realistic experimentation and demonstrations of non-operational prototypes (i.e., BA-4).

A related study by the National Research Council (NRC) Air Force Studies Board (AFSB) notes (REF 7, p50) that "successful technology developers separate technology development from product development. Technology is developed and matured first, and that is followed by the development of a product incorporating the new technology. These steps are not done concurrently." They state that developing technologies and weapons systems in parallel almost inevitably causes cost overruns, schedule slippages, and/or the eventual reduction in planned capabilities, adding that "simultaneously developing new technology within an acquisition program is a recipe for disaster.” (Emphasis added by the author.)

Finally, in a study by the Office of the Under Secretary of Defense Acquisition, Technology and Logistics (USD AT\&L) data on the performance of Major Development Acquisition Programs (MDAP) covering mid-1992 through 2011 was evaluated. The study included consideration of the impact of immature technologies and immature or changing requirements and specifications on program costs, work content, and schedule. They conclude (REF 8, p109) that "premature contracting without a clear and stable understanding of the engineering and design issues greatly affects contract work content stability and cost growth.” As part of the support for this conclusion, they note that of all the MDAPs during the preceding 19 years (REF 8, p51) "Development contracts with early work content stability exhibited significantly lower:

Total cost growth

Work content growth

Schedule growth
-61 percentage points

-82 percentage points

-31 percentage points."

BENS, GAO, and the NRC/AFSB conclude similarly that development and demonstration of prototypes should be accomplished as a means of refining requirements, gaining customer buy-in on the value of the product, and reducing the risk otherwise inherent in introducing new technologies. This is the stated purpose of BA4 funding, but it is in general not the way that the DON utilizes BA4 funding. Most BA4 funds are executed by PEOs in conjunction more often than not with BA5 or BA7 PORs, or with production programs. This practice (1) encourages programmatic technical, cost, and schedule risks, that should not be allowed within a BA5 or BA7 POR, by including unproven technologies in the POR planning and (2) facilitates the hiding of true POR costs by a blurring of funding boundaries. Moreover, by tying the bulk of the BA 4 funds to PORs, there is little opportunity for the development of demonstration prototypes that address speed to fleet needs but, and just as critically, that allow via the use of experimentation and operational demonstrations an iterative refinement of requirements for the new capability by engaging the warfighter, technologists, resource sponsors, and acquisition community. 
An argument can be made then that our current model, of generally having PEOs execute BA4 efforts within PORs, is inconsistent with good practices, acts to impede early introduction of new technologies to the fleet and force, and leads to cost and schedule problems. This practice should be changed.

Recommendation 1: Discourage acquisition category (ACAT) program risk taking by requiring an initial technology readiness assessment (TRA) to show all critical technology elements (CTE) to be at TRL 7 or higher. Encourage greater risk taking in S\&T transitioning programs, and in general stop S\&T development at a TRL 6. (See Appendix B for TRL definitions.)

While the major acquisition PORs and the S\&T programs are and should be managed as separate tracks, there does need to be in place a process that provides a transition path for those technologies that are determined to be appropriate for transition, in particular to mature them from a TRL 6 (validation in a "relevant" environment) to a TRL 7 (validation in an operational environment).

Recommendation 2: Manage the DON BA-4 program strategically, and as a distinct portfolio, to achieve DON speed-to-fleet goals, to address risk reduction for new technologies prior to inclusion in PORs, to gain warfighter buy-in of new capabilities via operational experimentation, to refine requirements prior to initiation of a POR or a mod to a POR; and do so separate from product development (BAs 5 and 7) program management.

This process should be resourced sufficiently to develop prototypes and to conduct experiments and demonstrations at scales that are necessary to validate and certify the value of a transition. The management of this process must be carefully designed and placed to maximize objectivity and minimize conflicts of interest. A process and approach to doing this will be proposed and recommended later in this paper (see Section 5).

The obvious third recommendation - to introduce DON corporate oversight over all levels of technology development (i.e., at least including BAs 1-4), and to develop a strategic plan for technology production and introduction (i.e., encompassing all of RDT\&E)—will be framed and presented in the next two chapters of this paper. 


\section{Establishment of Strategic Oversight}

The DON RDT\&E program spans BA 1 through 7. BAs 1-3 encompass the S\&T part of RDT\&E. BA 1-3 efforts within the DON are the responsibility of the Chief of Naval Research (CNR) and execution is managed on his direction by the Office of Naval Research (ONR). The CNR is responsible for the development, biennially, of a DON S\&T Strategic Plan (REF 9) that is socialized through the Secretariat, OPNAV, and HQMC staffs. It is then approved by senior DON leadership (i.e., the DON S\&T Corporate Board comprised, heretofore, of the Assistant Secretary of the Navy for Research, Development and Acquisition [ASN RDA], the Assistant Commandant of the Marine Corps [ACMC], and the Vice Chief of Naval Operations [VCNO]). The S\&T Corporate Board invoked the development of the first S\&T Strategic Plan with their insistence on having increased senior Naval leadership engagement in providing the fleet and force capability demand signals for S\&T and in ensuring that S\&T investments were consistent with future Naval needs. The plan lays out S\&T focus areas; the overall S\&T investment strategy; and the processes by which the Naval S\&T community can leverage innovations, meet emerging requirements, and quickly transition new technologies. The plan always has three principal goals:

1. Align Naval S\&T with the Naval mission and with future Naval capability needs;

2. Balance and manage the S\&T portfolio; and

3. Communicate the S\&T vision and approach to senior decision makers, key stakeholders, customers, and performers.

As a critical part of the S\&T Strategic Plan, S\&T Focus Areas are identified to represent at a high level the broad areas of scientific interest where senior Naval leadership agrees that the Navy and Marine Corps need selectively to be at the forefront, or at a peer level, or at an awareness-tracking level for specific areas of S\&T developments. The S\&T Focus Areas were developed iteratively, with underpinning from key DON guidance documents, in discussions between the CNR and the S\&T Corporate Board looking both at the Naval mission and at critical future Naval capability needs. The Focus Areas most recently approved (January 2012) by the DON S\&T Corporate Board are:

- Assure Access to the Maritime Battlespace

- Autonomy and Unmanned Systems

- Expeditionary and Irregular Warfare

- Information Dominance

- Platform Design and Survivability

- Power and Energy

- Power Projection and Integrated Defense

- Total Ownership Cost

- Warfighter Performance 
The Naval S\&T Focus Areas were developed to map the needs of the warfighter into the world of S\&T. The Focus Areas embody enduring themes and are:

- Developed from Naval needs,

- Sized for reasonable scale and magnitude, and

- Linked directly to warfighting functions.

The overall process for the development of the S\&T Strategic Plan is illustrated in Figure 3.

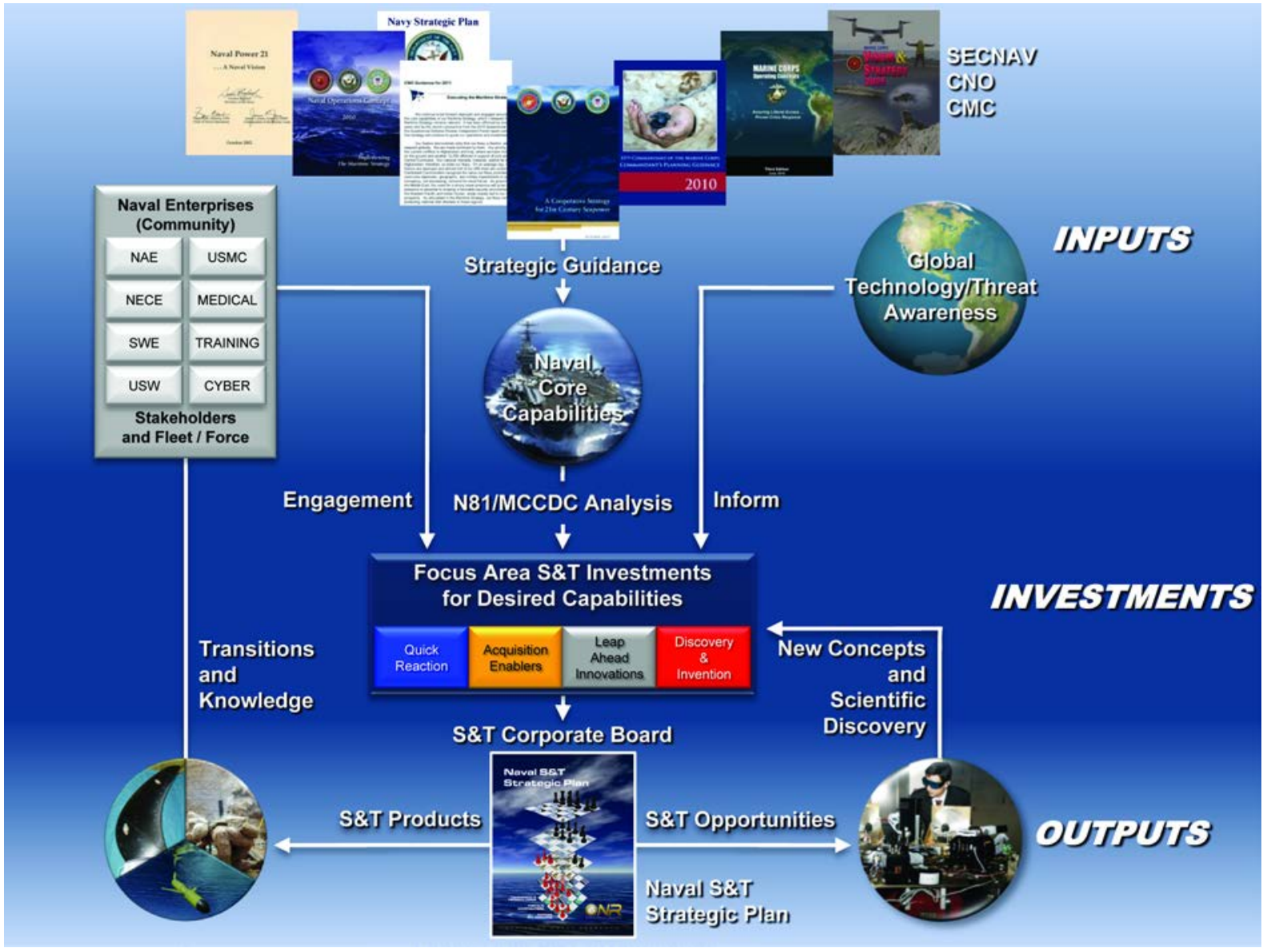

Figure 3: Naval S\&T Strategy Process

In addition to defining the Focus Areas for Naval S\&T investment, the S\&T Strategic Plan also lays out a strategy for investment by time horizon. There is recognition that a well-balanced Naval S\&T portfolio needs to address the pursuit of future game-changing capabilities, with an inherent investment in high-risk, but potentially high-payoff S\&T, through to the development of nearer term S\&T solutions to immediate needs of the acquisition community. Figure 4 shows the breakout of the DON S\&T Budget as a function both of time horizon and risk, the latter of which should be interpreted within S\&T as the exploration of opportunity for future capabilities.

The largest percentage of the DON S\&T budget, at 45 percent, is in the Discovery and Invention (D\&I) portfolio. D\&I includes Basic Research (BA-1) and early Applied Research (BA-2). With the goal of identifying new capabilities for the next generation of warfighter, and, with a horizon of 5 to 20 years, D\&I explores science to identify new technologies for those breakthroughs that 
eventually might be of warfighting value. D\&I also explores new technologies to identify potential new or improved warfighting capabilities; and it explores existing technologies to identify and explore new uses for these technologies to achieve new or improved capabilities. It is the "seed corn" upon which the rest of the DON RDT\&E program depends to maintain in the future the dominant Naval warfighting capability that we enjoy today. It is a hedge against uncertainty, and, indeed, is the primary mechanism open to DON by which the large ex ante uncertainties associated with new science and technologies can be reduced-all the more so now that industrial R\&D has become more and more focused on the bottom line for the next reporting period. In large part, industry no longer invests in Basic and Applied research unless it is funded by the Federal Government. All too often, industry also displays a willingness to let others pay for the development of breakthrough S\&T, and to accept with this the occasional risk of being second to market with a new product. In war, being second to market with a new capability can have greater impact than on a profit bottom line. Finally, with its international outreach, the D\&I portfolio is also the "canary in the mine" serving to alert DON to long-term foreign S\&T that, if not taken early advantage of by the United States, someday could pose a threat to the Naval warfighter.

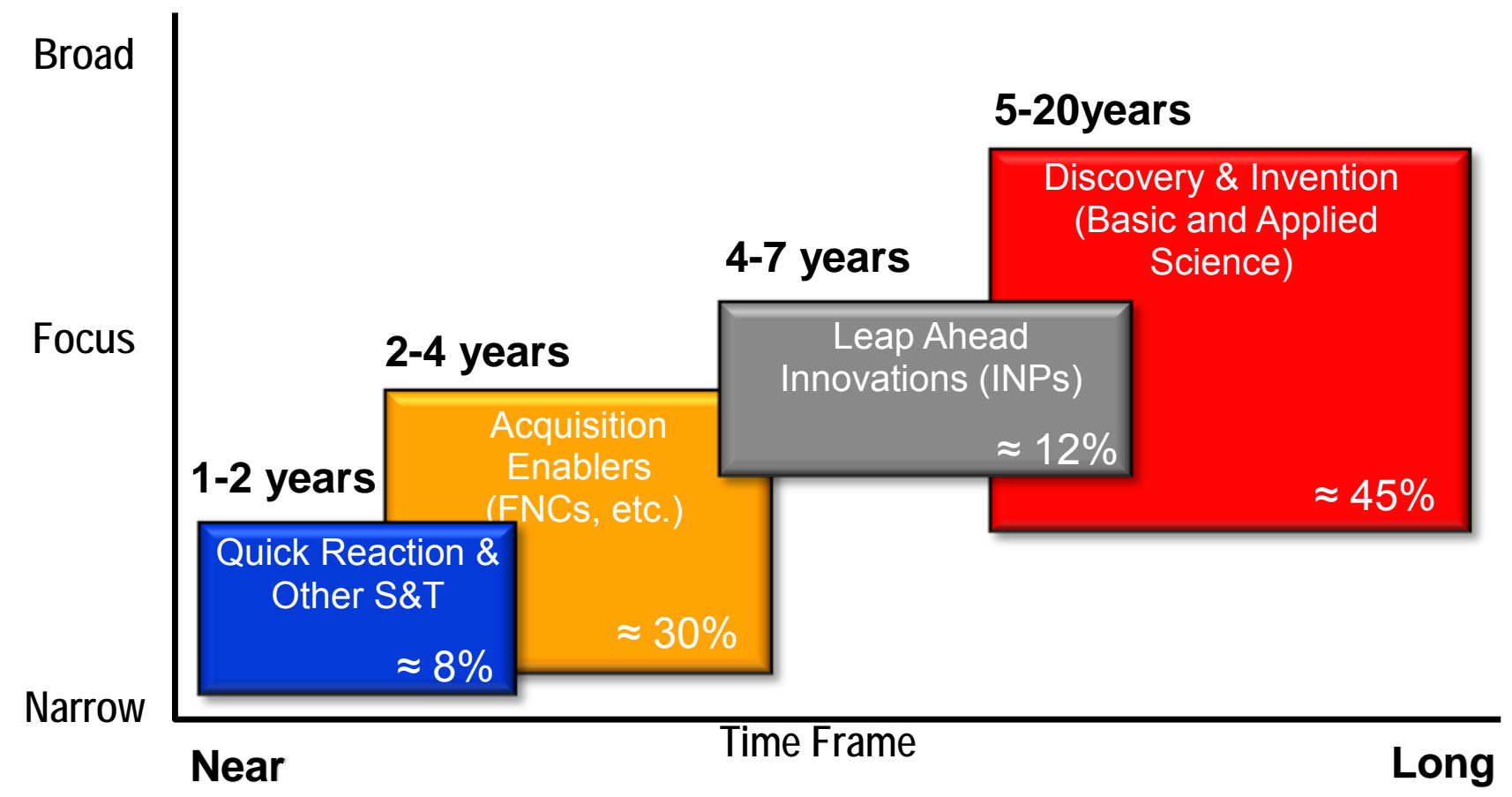

Figure 4: DON S\&T Investment Portfolio

The Leap Ahead Innovations portfolio, with 12 percent of the S\&T budget, has the next longest horizon in the S\&T budget; 4 to 7 years. Primarily consisting of the Innovative Naval Prototype (INP) program, this portfolio addresses the development of technologies that generally have arisen from the D\&I portfolio, that have been identified as having the potential to introduce game-changing capabilities in Naval warfare, but that require major/big-ticket investment to realize an integrated, realistic demonstration of feasibility. Accordingly, there are generally no more than 5 to 10 INPs ongoing at any one time. INP technologies generally are proposed initially by ONR scientists, but they require considerable vetting within OPNAV and/or HQMC and within the DON secretariat, and they have only been initiated after specific approval by the DON S\&T Corporate Board to ensure buy-in by senior leadership to what is a major S\&T 
investment commitment towards a game-changing capability. The DON S\&T Corporate Board annually tracks each ongoing INP projects and approves continuation based on continued technological successes, continued perception that the final capability will have significant/game-changing impact on Naval warfare, and commitments to and planning within DON to the eventual path for transition of the capability into the hands of our warfighters. Senior leadership in this process takes the time to evaluate proposed INPs, prioritize them, track them annually, and if they are successful, set their path to acquisition and eventual fielding.

The Quick Reaction (QR) Portfolio, with 8 percent of the S\&T budget, has the shortest horizon, generally well less than 2 years. It includes funding for the ONR TechSolutions program, for Navy and Marine Corps experimentation, for demonstrations and technology evaluations via the Marine Corps Warfighting Lab (MCWL), for the DON Science Adviser Program, and for responses to urgent universal needs statements (UUNS). The projects are off-the-shelf technology developments that are intended to address immediate needs identified usually by senior Naval leadership, but also regularly by individual sailors and marines.

The Acquisition Enabler (AE) Portfolio, with 30 percent of the S\&T budget, has a slightly longer horizon, of 2 to 4 years, to deliver a product out of S\&T. Where the INP portfolio should be considered as a "technology push," the AE portfolio represents a "requirements pull" of technology. Primarily comprised of the FNC program, the AE Portfolio works closely with OPNAV and the HQMC to gain identification from the warfighter of capability gaps that need addressing by S\&T. These capability gaps are vetted and formally approved by senior Naval leaders. FNC projects are proposed through ONR. Each proposed FNC project must identify a delivered capability that enables closure of some or all of an approved capability gap. As with the INPs, the proposed projects require considerable vetting within OPNAV, the HQMC and the DON secretariat. The projects are initiated after prioritized approval by the DON TOG that is chartered by the DON S\&T Corporate Board. The TOG is comprised of Deputy Chiefs of Naval Operations (DCNO) N8 (co-chair), N9 and N2/N6; Commanding General Marine Corps Combat Development Command (CG MCCDC) (co-chair); Deputy Commander Fleet/Forces Command (FFC); Principal Military Deputy ASN RDA; and the CNR; with other DCNOs and Deputy Commandants of the Marine Corps (DCMC) attending as appropriate to the list of proposed projects. (Marine Corps Forces Command [MARFORCOM] has been added recently to the TOG to join FFC in representing interests of the fleet and force.) The TOG annually tracks each ongoing FNC project and approves continuation based on continued technical success and, very critically, on continued and increasing maturation of planning for transition of the technical capability to either an acquisition program of record or to direct insertion into the fleet or force. The FNC program very specifically is requirements driven and is highly transition oriented. FNCs are primarily focused on advanced technology development (BA-3) efforts that in general mature and integrate technologies arising out of the basic and exploratory development efforts in DON and elsewhere in order to achieve and demonstrate technological feasibility of a specific warfighting capability. FNC projects range, for example, from anti-fouling bottom paints and battlefield medical monitoring systems, to quick-clot hemorrhage reduction materials and nextgeneration electronic warfare systems.

The percentages assigned to each of the major S\&T program categories have been iterated several times by senior leadership (i.e., the S\&T Corporate Board) over the last 10 years to find a good balance that maintains a steady stream of technologies and capabilities through to maturation. If the Acquisition Enabler portfolio was a significantly larger percentage of S\&T, 
more near-term capability issues could be addressed, but the pool of emerging technologies coming from the D\&I portfolio would then be reduced, to the detriment of being able to address then-current near-term capability issues in the future. The challenge to senior leadership of the DON has been, and is, to maintain the balanced ability to address near-term needs and contingencies while maintaining a sufficient scientific base to find those critical game-changing technologies that are required to preserve the qualitative superiority of the U.S. Naval forces into the future.

The DON S\&T program clearly has significant oversight commitment from senior Naval leadership including the establishment of strategic goals and direction; the identification of specific warfighter capability gaps; and very critically, for a significant fraction of the DON S\&T budget (i.e., the FNC and INP programs), the prioritization and approval of specific S\&T responses to Naval needs. There is even greater senior leadership oversight commitment, though on a piecemeal basis, for major acquisition programs within the DON RDT\&E budget. Notably, there has been no such senior oversight provided, however, for BA 4-7 non-ACAT programs (REFs 2, 3) or, outside of the S\&T programs, has there been regular review of the non-ACAT RDT\&E budget as required by DON regulations. The Naval Audit Service noted at the end of 2011 (REF 3, p1) that ASN RDA, CNO, and CMC "had not provided the required governance over non-acquisition programs. The Chief of Naval Operations' and the Commandant of the Marine Corps' resource sponsors were not conducting required annual requirement-basedassessments of non-acquisition programs nor providing an annual listing of non-acquisition programs to the” ASN RDA.

There is a greater concern, however, than just the lack of senior oversight of DON non-ACAT programs. There is a DON-approved S\&T Strategic Plan. There is a process for senior leadership approval and regular review of individual major ACAT programs. There is senior leadership oversight and approval required for the DON budget. We have many of the pieces of a formal strategy, but nonetheless, these do not add up yet to having a DON RDT\&E Strategic Plan. Rather critically, this lack of overall strategic oversight and direction essentially means that there is no DON prioritization of and plan for future directions and future capabilities that reaches across the breadth of the RDT\&E accounts and that ties them together as a coherent whole. This should be of much greater concern than the lack of oversight of non-ACAT programs, the latter of which can be considered as a symptom of the larger problem. (The "Navy Strategic Plan" is acknowledged. This document provides high-level guidance for the overall budget building and planning process for the Navy of today and for the very near future. However, it does not provide the strategic level of guidance needed specifically for RDT\&E planning and execution to define the Navy beyond the future years defense program [FYDP]. Similar comments apply to Marine Corps strategic planning.) As illustrated in Figure 5, the DON can be considered to be operating with an RDT\&E process that includes technology development, that includes product development, and that is expected to deliver new technology-driven capabilities to the Naval warfighter, but the process is lacking the critical guidance of overarching Naval RDT\&E Strategic Planning to motivate and knit together all of the pieces. 


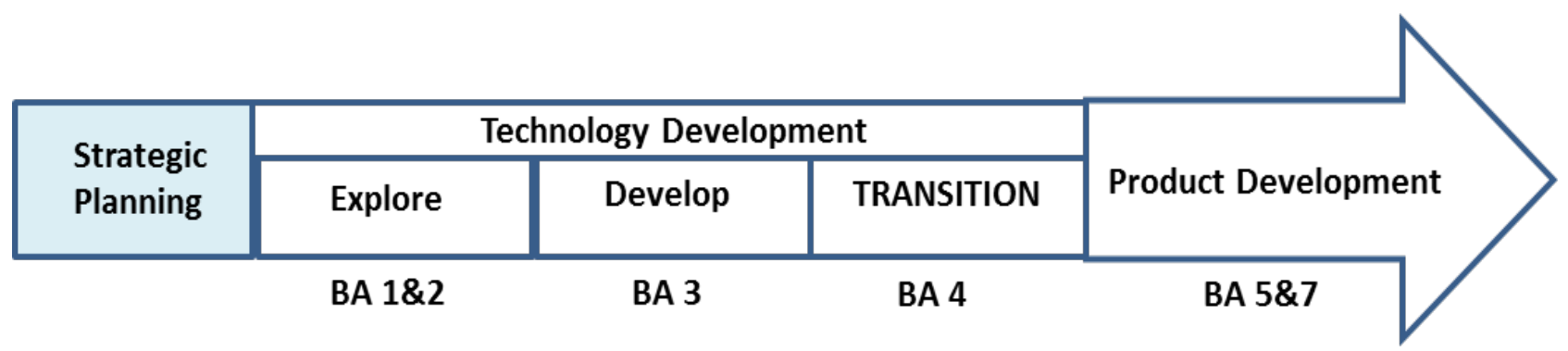

Figure 5: Process Flow for Technology Insertion

In considering the prospect of the establishment of an annual DON RDT\&E Strategic Plan, it is worth remembering again that DON in many ways is a high-technology company. In the current U.S. military scheme, the Combatant Commands (COCOM) are the end-use customer for the manpower, equipment, platforms, and weapons supplied by DON. The customer needs the services supplied to have specific capabilities, to be provided in sufficient quantities to address local circumstances, to be maintainable and readily sustainable, and to be of significantly better quality than similar services available to other customers (in particular, other potential adversaries). In addition, an underlying theme is that the provided services have to be affordable. Putting all of this together in a high-technology company demands a Strategic Plan that, at least as specifically for the breadth of RDT\&E, is not developed fully in DON. Given the adverse impact of having other suppliers provide to other customers superior services in any way, it appears that the development of an RDT\&E Strategic Plan is well worth doing.

The first step is the establishment of a senior oversight board that has sufficient stature and authority not just to review the RDT\&E program but to direct changes in the portfolio. As has been recognized, the Secretary of the Navy has recently signed a Charter for an RDT\&E Corporate Board that is charged with reviewing the RDT\&E program, developing a strategic plan, and recommending changes in the program and policies.

The newly established RDT\&E Corporate Board now has an opportunity to expand on the oversight currently provided for the DON S\&T portfolio to include an annual review of the BA4, BA-5, BA-6, and BA-7 portfolios. This should be done, not to have another level of reviews, but more importantly rather to inform senior leadership of what DON is investing in for the future of the Naval service and to enable the adjustment of program/project priorities to meet senior leaderships' longer term vision of the future. This priority ordering of the programs/projects within each Budget Activity portfolio and then across all portfolios is critically important as we enter a likely period of highly increasing pressure on the DON budget. In such circumstances, each community (e.g., enterprise such as Air) within DON should reasonably and properly be expected to do its best to preserve the critical capabilities offered to the Naval warfighter from within that community. It appears somewhat unlikely to expect a community to volunteer that the lowest priority funded capability/system/program from within that community is less important than the highest priority un-funded capability/system/program from within another community. On a microcosm level, this latter point is what led the S\&T Corporate Board in circa 2005 to take budgetary approval authority away from the individual FNC integrated product teams (IPT) and assign to the FNC TOG the authority to approve annually any new FNC starts according to then current DON perceived priorities as opposed to the valid but more parochial priorities from within each IPT. What was done for the FNC 
program was the establishment of strategic oversight. This can and should be done for the balance of the RDT\&E accounts.

The lack of full breadth strategic management of RDT\&E can be argued as a major contributor to the so-called "valley of death" between the acquisition and the S\&T communities (REF 5); there is significant evidence that it leads to the hiding of true program costs and program technology readiness (REFs 5, 10); and there are good arguments to indicate that it is a major impediment to the early introduction of critical capabilities to our warfighters as evidenced by the increasing demand for speed to fleet and force.

Recommendation 3: Establish a DON RDT\&E Corporate Board with the charter to provide strategic oversight, establishment of prioritization, and management of the DON RDT\&E portfolio and require the Board biennially to develop and publish a DON RDT\&E Strategic Plan.

While a Charter has been signed that addresses this recommendation at a high level, the implementation of the Charter has yet to be accomplished, and the specifics of the implementation will determine whether this Board can provide strategic management oversight to the overall DON RDT\&E programs or just be another high-ranked review panel.

The next chapter will develop the structure of a prospective DON RDT\&E Strategic Plan. This will be followed by a chapter defining a recommended DON RDT\&E management structure that specifically includes separating out management of the BA-4 portfolio along with recommendations on how this can be accomplished efficiently within the current DON organizational structure. 


\section{A DON RDT\&E Strategic Plan}

The RDT\&E Strategic Plan should be about the Naval and Marine Corp warfighter, but it should be about the Navy and Marine Corps warfighter of the future, not of the present. Capabilities initiated under the plan may be demonstrated within the FYDP, but likely, production in quantity for new capabilities generally will and should be expected to occur outside the FYDP. To this end, the plan needs to provide direction in part for the next Navy and Marine Corps, and also for the Navy and Marine Corps after next, which entails greater risk if specifying precise needs and thus calls for an ability to adapt over time to mission-critical vectors rather than well-defined end points. The plan should address the long-term and fundamental roles for the DON warfighter and, as with the S\&T Strategic Plan, should have three principal goals: (1) align Naval RDT\&E with the Naval mission and with future Naval capability needs, including the demand signals for innovation and for cost cutting; (2) balance and manage the RDT\&E portfolio; and (3) communicate the RDT\&E vision and approach to Naval decision makers, key stakeholders, customers, and performers. The DON S\&T Strategic Plan provides a potential starting point for this RDT\&E Strategic Plan, already having been approved by the DON S\&T Corporate Board (now, with the addition of the Undersecretary, re-named and re-chartered as the RDT\&E Corporate Board).

\subsection{Aligning Naval RDT\&E with the Naval Mission and with Future Capability Needs of the Naval Warfighter}

The documents Naval Power 21 (REF 11), Sea Power 21 (REF 12), Marine Corps Strategy 21 (REF 13), and Cooperative Strategy for the 21st Century (being updated) provide a good basis for definition of cross-cutting thrusts for the Naval RDT\&E Strategic Plan. These documents formed the basis for the current FNC IPTs (approved by the S\&T Corporate Board) but with the addition of several new IPTs, beyond the construct of Sea Power 21, to broaden the coverage to the full range of the perceived needs of the DON, including such Naval enterprise needs as affordability and maintainability; maneuver warfare; health, manpower, and training; and power and energy. The list of current FNC IPTs should be considered as a starting point in the discussion of the thrust areas (or focus areas) to be included in a Naval RDT\&E Strategic Plan. These FNC IPTs, as of November 2013, are:

- Sea Shield - Missile defense, anti-submarine warfare (ASW), mine counter-measures (MCM), and fleet/force protection technologies - global defensive assurance

- Sea Strike - Weapons, aircraft, and expeditionary warfare technologies - precise and persistent offensive power

- Sea Basing - Logistics, shipping, and at-sea transfer - operational independence

- ForceNet - Command, control, communications, computers, intelligence, surveillance, and reconnaissance (C4ISR); networking; navigation; decision support; and space technologies -architectural framework for Naval warfare in the information age

- Naval Expeditionary Maneuver Warfare - Warfighting capabilities of Naval ground forces, with special emphasis on regular and irregular warfare 
- Capable Manpower - Matching sailors and marines to the right jobs, designing intuitive systems, and training for mission-essential competencies

- Force Health Protection - Protecting sailors and marines and reducing morbidity and mortality when casualties occur

- Enterprise and Platform Enablers - Cross-cutting technologies to lower acquisition, operations, and maintenance costs

- Power and Energy - Energy security, efficient power and energy systems, high energy and pulse power

Of note, each of these IPTs is comprised of a senior flag officer from OPNAV and from HQMC as co-chairs, an acquisition flag or senior executive service (SES) (generally a PEO), a Fleet/Forces Command representative, and a technology representative (generally an ONR SES department head).

At various times, the FNC TOG, along with more senior service leaders, has explored alternative structures for the FNC IPTs. Alignment with the Navy Enterprise model has been considered, as has a simple alignment with the resource structures within the OPNAV and HQMC staffs. So far, all previously considered alternatives have been rejected as not adequately addressing the crosscutting breadth of requirements for the Naval S\&T portfolio, specifically as it is interfaced with the Naval acquisition community. When directly asked by the author about a change to either of the above alternatives, former CNO Admiral Gary Roughead said that he did not like the Sea Power 21 model, but that the IPT structure should remain unchanged because he "did not have a better alternative yet to address the cross-cutting needs of the Navy." A more recent alternative that has proven to have some stability within DON is the Universal Naval Task List (UNTL). This structure would have the following thrust areas:

- Maneuver

- Intelligence

- $\quad$ Fires

- Logistics

- Command and Control

- Force Protection.

The structure should be considered as viable as a starting point for development of thrust areas, though consideration should be given to some modifications as was done previously from the Sea Power 21 model basis for the FNC IPT structure. Logistics, in particular, seems to be an "everything else" category that likely warrants further articulation (e.g., medical/health issues as well as manpower and training issues could be split out from logistics for better control and visibility).

Whatever the final make-up of the thrust areas within the RDT\&E Strategic Plan, the structure should be such as to encompass the breadth of RDT\&E efforts within DON, including S\&T. With the thrust area structure defined in the RDT\&E Strategic Plan, IPTs can be assigned for each of the thrusts as part of the RDT\&E Strategic Plan and a process established within the Plan for the IPTs to annually assess the ongoing BA-4, $-5,-6$ and -7 portfolios, as divided among the 
IPTs, to support an annual review by the Corporate Board without tying up the very senior Board membership in too much detail. If the FNC IPT structure is chosen, then these same groups (already in existence) could combine this R\&D review with the annual review of FNC programs. As with the FNC process, the IPTs are well situated not just to assess ongoing programs and provide recommendations to the RDT\&E Corporate Board on these programs, but also to do an initial screening of proposed new projects for the FNC, INP, and BA-4 portfolios that could then be subject to review and approval by the RDT\&E Corporate Board. This latter process was recommended earlier in this paper (Recommendation \#2) and is one that should be delineated explicitly in the RDT\&E Strategic Plan. A specific prospective implementation approach for this will be discussed in the next chapter.

\subsection{Balancing and Managing the RDT\&E Portfolio}

Data on the current balance within the RDT\&E portfolio (Figure 1) is translated in Figure 6 into a format similar to that of the S\&T "4-Box Chart" developed within the S\&T Strategic Plan. The chart shows the percentages of the total RDT\&E in PB14 for each box category, and shows in parenthesis that percentage as relative to the DON topline in PB14. A prospective, revised, RDT\&E "4-Box Chart” is proposed later in this chapter.

The BA 1-3 box represents the S\&T part of the RDT\&E portfolio. This is DON's "seed corn" for future technologies, and is also the "warning track" for avoidance of technology surprises. BA-1, or Basic Research, includes scientific study and experimentation directed towards increasing fundamental knowledge and understanding in fields related to long-term national security needs. BA-2, Applied Research, includes the systematic exploration and development of useful materials, devices, systems, or methods aiming to meet or address general mission area requirements. It also includes translation of promising basic research into potential solutions for

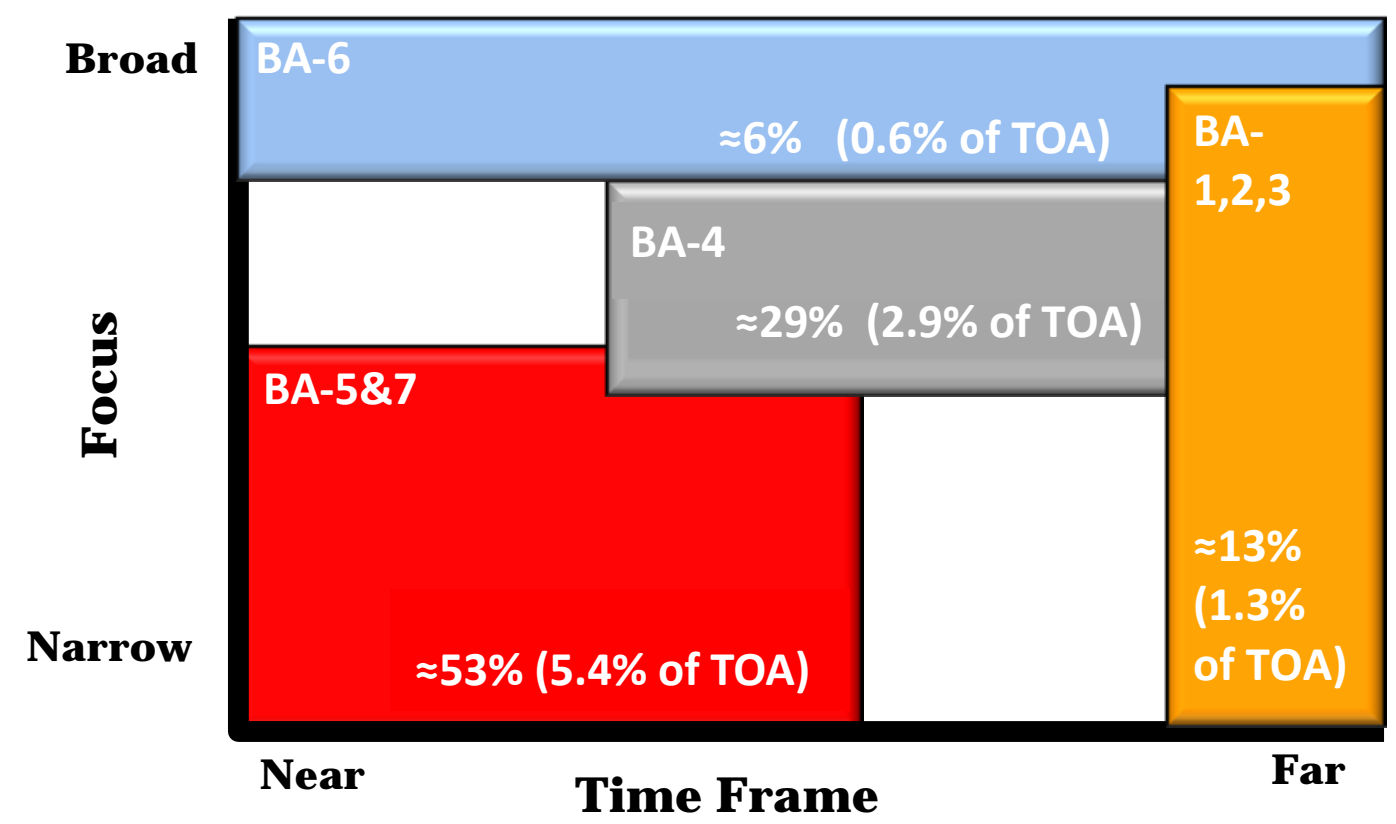

Figure 6: PB14 DON RDT\&E Portfolio 
broadly defined military needs. BA-3, Advanced Technology Development, includes the development and testing in a laboratory environment of advanced components, subsystems, or system models having a direct relevance to military needs. Projects in this category do not necessarily lead to subsequent development and procurement phases, but do have the goal of demonstrating technology as suitable for transition out of S\&T. The relative size of the S\&T portfolio has been the subject of extended discussions within DON, with the Office of the Secretary of Defense (OSD) (and in particular with Assistant Secretary of Defense (Research and Engineering) [ASD R\&E]), and with Congress. It has shrunk noticeably over the last several decades as a percentage of the DON topline, holding to a relatively flat line as the DON budget significantly increased, and heretofore had been negotiated at a stable approximately $\$ 2$ billion per year, inflation adjusted, in the current FYDP.

The BA-4 box is the Advance Component Development and Prototype (ACD\&P) portfolio for DON, intended to support evaluation of integrated technologies, representative modes, or prototype systems in a realistic operational environment to refine and demonstrate military value of the technology, to evaluate and solidify requirements and specifications, and a priori to reduce the risk of insertion of the technology into a major or complex system development. Experimentation with and demonstration of prototypes in a realistic operational environment should also be the enabler for speed-to-fleet/force early insertions of prototypes in limited quantity, where needed, to address immediate and urgent operational needs. This portfolio is not currently managed as a distinct portfolio. PB14 has BA-4 funding set at approximately 29 percent of the DON RDT\&E total, or 2.9 percent of the DON topline. The roughly $\$ 4.5$ billion of funds primarily is distributed into various PORs and generally executed by a PEO as part of a (BA-5\&7) POR. Changes to the current BA-4 management will be the primary focus of the remaining chapters of this report. BA-4 use as defined immediately above (and see also legal definitions in Appendix A) is posited as more beneficial to the DON than the current distributed usage, and specific recommendations will be proposed that should as well at least be outlined in the RDT\&E Strategic Plan. Serious consideration also should be given to increasing significantly the relative and absolute size of the BA-4 portfolio to better enable a planned process for resolution of the regular needs for speed-to-fleet/force insertions and, though less immediate but perhaps even more critical, for the simple reason that we do not have adequate funds to address being fully equipped for every contingency that could arise in the varied geopolitical world in which we live. Given the huge breadth of uncertainties, we would be remiss if we did not to the fullest extent possible at least have developed, and operationally assessed, some possible solutions to these varied circumstances, and have as many as possible of the solutions "on the shelf" and ready for procurement should an exigency warrant them. This is one of the valuable outcomes enabled by BAs 1-4. We can identify possible problems, develop solutions to them, experiment with and evaluate the solution, and gain warfighter buy-in on the solution without committing to a major development acquisition program. The fully vetted solutions/capabilities could then be held either as risk mitigation or as strategic reserve opportunities, subject to quick-reaction procurement if needed. DON, thus, can effectively and affordably hedge its bets against uncertainty associated with at least some prioritized contingencies.

The BA-5\&7 box includes the System Development and Demonstration (SDD) and Operational System Development portfolios. These budget activities provide for the conduct of engineering and manufacturing development efforts leading to production representative articles (i.e., production prototypes) to be used in the validation of requirements (e.g., via live-fire test and 
evaluation [LFT\&E] and initial operational test and evaluation [IOT\&E]) of new systems (BA-5) or of upgrades to existing systems (BA-7). BA-5\&7 efforts are expected to lead to an approval for full rate production and should anticipate production funding upon successful completion of efforts. Roughly $\$ 9.5$ billion has been budgeted within PB14 for BAs 5\&7, which is 53 percent of the DON RDT\&E budget, or 5.4 percent of the DON total obligation authority (TOA). As with BA-4, this box is not managed specifically as a distinct portfolio, but nevertheless, with the exception of the non-ACAT programs, it is closely managed by senior leadership through the MDAP and related processes. This portfolio should be expected to decrease in relative size as the DON procurement budget becomes increasingly constrained, and with that, the ability to introduce in quantity new systems and/or platforms as opposed to completing procurement of already developed systems and platforms. The ratio between BAs 5\&7 could also be expected to shift noticeably if the Department decides to focus critical procurement funds on securing quantities of and upgrades to currently developed systems rather than introducing perhaps smaller numbers of entirely new systems. Upgrades to the existing systems conceivably could be given priority, with reduced funding for entirely new systems to be reserved for when a new system or technology has game-changing impact. These conversations do not occur today, and they need to occur.

Finally, the BA-6 box is RDT\&E Management Support. This is intended to include RDT\&E facilities and laboratories maintenance and upgrades, operation and maintenance of test aircraft and ships, and general support of RDT\&E management. Approximately $\$ 0.9$ billion has been budgeted in PB14 for BA6, which is roughly 6 percent of RDT\&E funding, or 0.6 percent of DON TOA. The BA-6 personnel costs have been looked at extensively by OPNAV N1, but the overall state of the RDT\&E infrastructure, to include laboratories and test facilities and platforms, warrants serious attention that has not been provided so far. However, this latter issue, while very real, will not be addressed further in this paper.

The RDT\&E "4 Box Chart" should be a critical part of the DON RDT\&E Strategic Plan, recognizing the evolving budget crisis while recognizing the increasing risk to our military planning. Serious consideration should be made to addressing those dual, related risks by a gradual redeployment of some RDT\&E funds away from BAs $5 \& 7$ and into BA-4. This will enable DON to have operationally demonstrated capability available to address the fullest range of potential risks, while at the same time minimizing the impact on DON procurement budgets. It will do so by focusing procurement funds on buying quantities of current systems and platforms, on upgrades to those existing systems and platforms, and on gaining but at a slower rate the introduction of new systems and/or platforms with focus only on those that offer affordable, breakthrough capabilities. The world certainly is rife with turmoil and strife, in particular in the equatorial regions, but there does not appear to be likelihood near term of a major conflict. A relative increase in the BA-4 budget could provide DON the opportunity to better explore solutions to potential perceived shortfalls against a near-peer adversary and to identify and develop potential advantages over such an adversary. A prospective RDT\&E "4-Box Chart" is included in Figure 7 for consideration.

In this portfolio redistribution, the BA-1/2/3 portfolio is proposed to be left at level funding in PB13 real dollars, the BA-4 portfolio is significantly increased as a strategic capabilityopportunity mechanism and as a risk-reduction mechanism, the BA-5 portfolio is significantly decreased while the BA-7 is left relatively intact or slightly larger to reflect a shift away from introduction of new capabilities while preserving upgrades to existing systems and platforms 


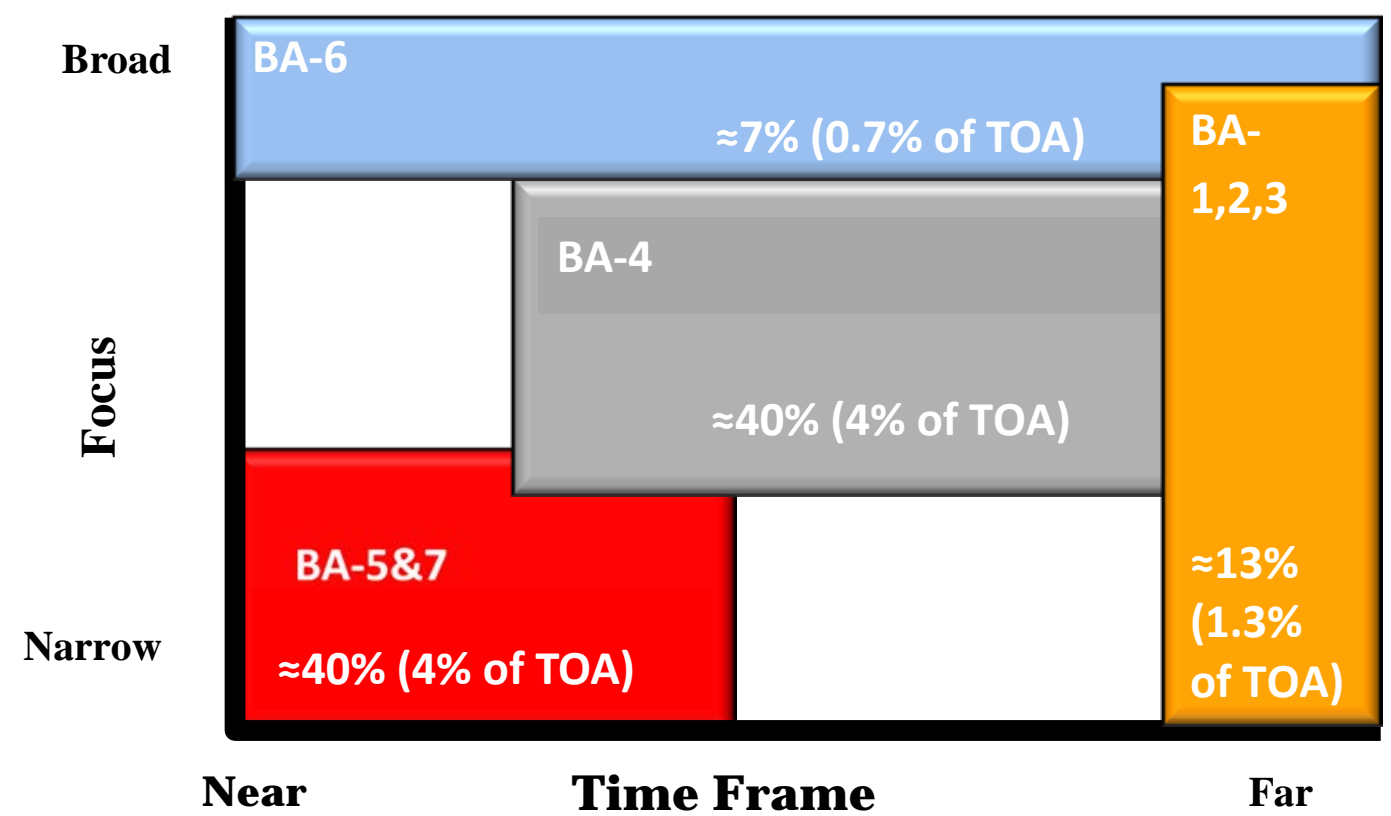

Figure 7: Proposed Future DON RDT\&E Portfolio

(still a net decrease for the combined BA-5\&7 portfolios), and the BA-6 portfolio is increased slightly to improve T\&E capability within DON.

In summary, other than the S\&T portfolio, the major part of the DON RDT\&E portfolio currently appears to be managed at the individual program level, and without full recognition of the role in particular that BA4 can and should play in both reduction of developmental risks and in the performance of early experiments and demonstrations that refine requirements definition and that gain end-user buy-in, while also addressing speed-to-fleet/force issues. As with any high-tech firm, DON can better be served with a strategic planning vision that recognizes the constituent stages of the development cycle and manages them deliberately as individual stages, each with a specific function to perform as part of the whole. A reduced, but still significant, part of the RDT\&E budget is recognized as needing to be devoted to the development within BAs-5 \&7 of production prototypes of systems and/or platforms then to be produced in quantity to meet relatively near-term requirements of the fleet and force. The percentages devoted to the other parts of the RDT\&E budget, however, are significantly critical to the DON both as it executes the RDT\&E program (as in BA-6 manpower and facility costs) and in particular as it prepares for and explores the future needs of the fleet/force through the exploration, (BA-1/2), development (BA-3), and maturation/transition and demonstration (BA-4) of new technologies and resultant new capabilities. As noted in the discussion around Figure 2 (see also REF 1), the balance of RDT\&E funding should be the result of a conscious and strategic decision, looking not just at the present demand signal, but also anticipating the future needs and future risks of the Naval service. The percentages shown in Figure 6 are those from PB-14. Figure 6, but preferably something closer to Figure 7, should be a critical part of the DON RDT\&E Strategic Plan. The percentages assigned to each category should be iterated and then approved by senior leadership as the best balance to serve the needs of the fleet/force of today, while also preparing the way for the capability superiority of the fleet/force of the future. 


\subsection{Communicating the RDT\&E Vision and Approach to Naval Decision Makers, Key Stakeholders, Customers, and Performers}

DON is nothing if not process driven and clearly a vision for the future of the Naval forces, and an approach to achieve that vision, will never come to fruition if it is not promulgated officially and disseminated widely. The envisaged RDT\&E Strategic Plan should set direction for the S\&T community (i.e., a vision of warfighting needs), identify a process for the maturation and transition of new technology to be transitioned to Naval developers (PEOs), and define a mechanism for those developers to gain priority endorsement of and funding for subsequent completion of acquisition-ready systems and platforms for the fleet and force. In other words, it should address the entirety of the RDT\&E portfolio and community. The RDT\&E Strategic Plan should motivate the S\&T community and should challenge the acquisition community to meet the near- and far-term capability needs of our Naval warfighters, and it should provide a clearly defined path for the identification, maturation, and final development of the new technologies needed now and in the future to meet those needs. The RDT\&E Strategic Plan also will provide a starting point for a periodic iteration by senior Naval leaders of the perceived strategic needs of the Naval forces. In addition, it will provide to DOD leadership, the COCOMs, and Congress a single document unifying the Naval RDT\&E programs, identifying a vision for the future, and a clear path to get there. The potential value of having such a unified RDT\&E Strategic Plan in particular in budget negotiations with Congress should not be underestimated. More immediately, if the RDT\&E management process changes recommended in this paper are to be adopted, the presentation of the RDT\&E Strategic Plan to Congress should be considered as critical in laying out the proposed changes and then garnering support for a new approach to governance and execution of the RDT\&E portfolio.

Recommendation 4: The DON RDT\&E Strategic Plan should identify the leadership vision for future directions of the Naval services, defining specific processes for selection, initiation and management of those future directions, and laying out a balanced investment plan allotting RDT\&E funds to address mid- and long-term investment needs.

In the next chapter, a specific management structure will be proposed for the DON RDT\&E program to enable implementation, efficiently and with strong oversight by senior leadership, of the DON RDT\&E Strategic Plan and vision. As noted earlier, at least the outline of this management structure should be included explicitly in the RDT\&E Strategic Plan. 


\section{RDT\&E Management Implementation}

This chapter will focus on the structure for, and management of, the DON BA-4 portfolio. It will start by reiterating the recommended role within the DON of the BA-4 portfolio, propose a structure for the BA-4 portfolio, and identify a prospective governance process. Next, the chapter will define a roll-in period for the new process that supports quick initiation of the new roles for the BA-4 portfolio, while avoiding "breaking" programs approved under the current processes. Finally, it will provide discussion on how and why the proposed BA-4 governance can, and should, be considered for extension to include BAs 5/6/7.

\subsection{The Proposed Role of the BA-4 Portfolio}

From the earlier Recommendation 2 in Chapter 2, the DON BA-4 portfolio (the "Transition" part of an RDT\&E portfolio as illustrated in Figure 8), should be oriented via the use of experimentation and operational demonstrations to support:

1. Speed-to-fleet/force;

2. Proof of value (i.e., warfighter buy-in on new capabilities);

3. Requirements/specifications refinement prior to POR initiation; and

4. Risk reduction for technologies, prior to their introduction into a POR.

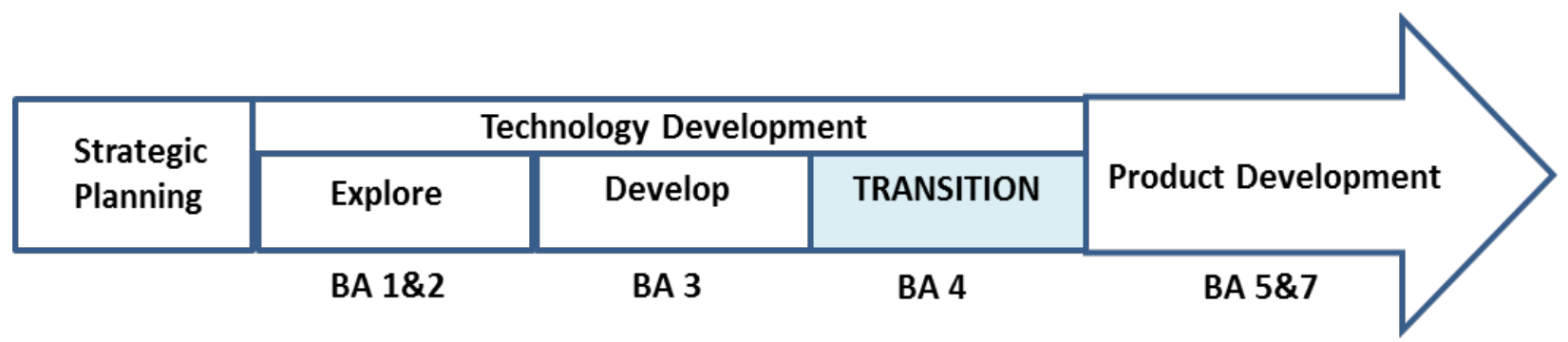

Figure 8: Process Flow for Technology Insertion

Considering the first role for BA-4, we demand "speed to fleet" but we budget for a slow process with first delivery to the fleet or force at low-rate initial production (LRIP), at the end of a lengthy acquisition development process. We can provide limited "prototype" fielded capabilities much sooner if we quite legally step outside of our normal DOD/SECNAV 5000.2 progression, while staying well within the allowable confines of 5000.2, that is, if we are willing to change business as usual. The current rapid-fielding programs address some limited specific exigencies but do not address the broad issue of getting new technology-driven capabilities into the hands of our warfighters quickly. The laws and regulations applying to BA-4 allow us very early on to introduce "demonstration" quantities of new technology-driven capabilities directly to the warfighters if we just choose to do so. The use of these early field demonstrations of prototype components and capabilities then can significantly improve our ability quickly to respond ("speed to the fleet") to adversary innovations and accelerate introduction of our own new and innovative capabilities that, when done sooner, can force our adversaries to a defensive role, that is, having to respond/react to us. If our warfighters value the new capability, and its usage becomes critical, we can continue providing limited quantities for extended "demonstration" purposes, with the primary disadvantage of likely needing contractor or 
Government Laboratory engagement for maintenance and operations support—but the capability notably will be provided very early, when critically needed. (Interestingly, this is the model for capability introduction that extensively was used in our last declared war, more than 70 years ago.) This "beta testing” process is one widely used to great value within the high-tech world. Prototypes that gain acceptance by the customer are continued in development and then released widely within the marketplace. Prototypes that do not provide perceived value either are changed significantly or are dropped from further product development and are not produced in quantity for the marketplace. As in the commercial world, the early introducer can set the standard in the marketplace and can drive reactions by competitors, rather than having to react to innovations introduced by competitors.

The second and third roles for BA-4 all are closely related. With the current very limited use of pre-Milestone B demonstrations of new technologies, the fleet/force generally is not engaged in early experimentation and evaluation of new technology being developed for them. More typically, the first opportunity for an operator to evaluate a new technology-driven-capability is at either a technical evaluation (TECHEVAL)/operational evaluation (OPEVAL) or more likely with LRIP deployment. Early experiments and demonstrations can gain critical fleet/force assessment, endorsement, and support for an acquisition program starting into the development process (and can also point to the need to avoid initiation of an acquisition program of insufficient value). Pre-Milestone B evaluation of "integrated technologies, representative modes or prototype systems in a high fidelity and realistic operating environment" (from the definition of BA-4) by elements of the fleet/force, moreover, can enable a meaningful trade-off between the fleet/force, acquisition community, resource sponsors, and industry, of technologies and operational requirements. This trade-off supports establishment of firm system design requirements and specifications that point to an affordable, operationally effective and valuable, and development-risk-acceptable acquisition. The lack of firm specifications, or worse, the introduction of changes to contracted specifications, is a major cause of contract cost overruns and schedules slippages. Early input from the fleet/force to lock down specifications significantly, however, has been lacking in the current acquisition process. As noted earlier in this paper, the NRC in a study of U.S. Air Force (USAF) technology development (REF 7, p4) strongly recommended the creation of an environment that "allows stakeholders-warfighters, laboratories, acquisition centers, and industry - to trade off technologies with operational requirements prior to Milestone B." Some of the reasons behind this recommendation can be backed up with broadly based statistical data from within DOD. The Under Secretary of Defense for AT\&L (USD AT\&L) in a 2013 report (REF 8, p51) evaluated DOD MDAPs between June 1992 and December 2011 and found that "where work content was stable the first year, we found that cost and schedule growth also were more stable", that is, the requirements and specifications did not change. In the report, the USD AT\&L compared MDAPs that had "stability" throughout their first year with those that did not and displayed the following comparisons in favor of the MDAPs having requirements and specifications stability:

Total cost growth $\quad-61$ percent

Work content growth -82 percent

Schedule growth $\quad-31$ percent.

These statistics on real MDAPs within DOD make a compelling case for refinement and stabilization of requirements prior to BA-5 or BA-7 program initiation. As a final note, Secretary 
of the Navy Mabus (REF 14) has underlined that in our dealings with industry, they owe us a well-built product delivered on time and at a fair cost, and we owe them well-defined and stable specifications and requirements for those products.

While the second and third roles for BA-4 are closely related, they need not always overlap, and indeed one reason for why and when they should not overlap is that the BA-4 portfolio offers DON the opportunity to try out new capabilities in an operational environment, gain warfighter buy-in on the capability, and then put that capability "on the shelf" for possible later use. This may seem to be a waste of resources but it should be considered as a risk reduction mechanism addressing the fact that our budget and the full range of needs for our military increasingly do not coincide enough. With fully tested capabilities tried out by the warfighting community, those vetted capabilities that may not be addressing the current highest perceived risks will be available for quick supply in the event that the risk prioritization changes due to some action by an adversary or by a shift in national focus. USD AT\&L Kendall in a presentation at the National Press Club (REF 15) endorsed this use of demonstration prototyping where there was prior acknowledgement that there was no planned follow-on procurement. Consideration should be given in this declining budget environment to having a significant fraction of the BA-4 portfolio devoted to this risk reduction role.

The fourth role for BA-4 is in achieving risk reduction for technologies, prior to their introduction into a POR. This is closely related, but nevertheless different in scope, from the previous two roles. Precisely understanding requirements, and carefully and correctly translating these to measurable specifications, does not provide indication that the technology chosen to underpin a system or component is ready for relatively risk-free product development. We are reminded repeatedly that early demonstration of technologies in an operational environment (i.e., BA-4 efforts) significantly serves to reduce subsequent development risk by supporting the assessment of the capability and demonstrating the maturity of the underlying technology (i.e., TRL7). The aforementioned NRC/AFSB report (REF 7, p50) notes that "Developing technologies and weapons systems in parallel almost inevitably causes cost overruns, schedule slippages, and/or the eventual reduction in planned capabilities." The report on defense acquisition reform, cited in Chapter 2, by BENS (REF 6, p11) strongly recommends that Milestone $\mathrm{B}$ be initiated only after the concept is clear and the technology is proven. The GAO study on best business practices among high-tech companies reiterates (REF 1, p12) that technology should be handed over to product development, that is, a PEO, only after the underlying technology has been demonstrated in an operational environment (TRL7). Again, in contrast to the noted best practices, DON allows a POR to be initiated with critical technology enablers (CTEs), that is, the critical underlying technologies, not proven in an operationally realistic environment (i.e. at TRL 6 or lower). The TRA process within DON shows many instances of this and the practice is justified within DON by incorporation of a BA-4 technology maturation effort within the POR, ongoing in parallel with the BA-5 or BA-7 development. The result is that the BA-5 or BA-7 program then is critically dependent for its own success on the timely and successful completion of the higher risk BA-4 effort(s). To paraphrase the NRC, by this parallel development process we almost inevitably invite cost overruns and schedule slippages.

In closing, it should be noted that the initiation of a well-defined/well-specified POR provides value in enabling industry the basis and the challenge to provide firm proposals for the development of a well-understood and valuable product, based on demonstrated mature 
technologies, and not subject to the subsequent changes in scope that lead to cost overruns and schedule slips.

\subsection{The Proposed Structure and Governance Process for the BA-4 Portfolio:}

In Chapter 2, a technology insertion process flow model (see Figure 2 or Figure 8) was identified that progressed from a start with Strategic Planning, then proceeded to Technology Development (Exploration - BAs-1\&2; Development - BA-3; and Transition - BA-4), and on to Product Development (BAs-5\&7) before the final product (system, platform, etc.) is subject to Procurement in quantity.

Elements of an RDT\&E Strategic Plan are explored in Chapter 4. These include a delineation of prospective Naval thrust areas, a recommendation that the funding allocated to RDT\&E be subject to a very deliberate balancing by the RDT\&E Corporate Board, and a note that there should be included in the Strategic Plan a definition of a mechanism to enable the Corporate Board to explicitly (REF 16) "establish and maintain a coordinated and comprehensive RDT\&E program to meet Naval goals," and to manage technology development and product development (the RDT\&E portfolio) to “ensure(s) the Department's RDT\&E budget and execution decisions support near- and long-term (procurement) programs.”

The mechanisms for the maintenance of (REF 16) "a coordinated and comprehensive RDT\&E program" are explored in Chapter 3 at least for the S\&T portfolio (Exploration - BAs-1\&2, and Development - BA-3). A comparable mechanism will now be proposed for the Transition (BA4) portfolio that is based somewhat on the existing structure of the BA-3 FNC program that was established by the Navy, the Marine Corps, and the DON secretariat under the authority of the former S\&T Corporate Board (VCNO, ACMC, and ASN RDA). Two main reasons provide motivation to propose this particular BA-4 Portfolio management structure, and also a modification to the BA-3 FNC management structure. The first is that from Recommendation 2, a process is being proposed to manage separately the entirety of the BA-4 portfolio as a strategic and distinct portfolio for all the reasons previously discussed. The second is that doing so enables use of an existing DON management structure that already combines the resource, requirements, acquisition, and fleet/force communities most directly responsible for RDT\&E, and that, thereby, does not require yet another flag-level structure to be established and staffed.

The envisaged BA-4, and current BA-3 FNC, management structure has the RDT\&E Corporate Board as the approval authority both for requirements (through the RDT\&E Strategic Plan) as well as for approval of prioritized program proposals to be provided respectively to the Navy and Marine Corps headquarters staffs for funding. Underneath the 4-star RDT\&E Corporate Board there is envisaged to be a 3-star TOB prospectively comprised of OPNAV N-8 and CG MCCDC as co-chairs; DCOM FFC, MARFORCOM, Principal Military Deputy (PMD) ASN RDA, and OPNAV N2/N6 as permanent members; OPNAV 093, Deputy CNOs, and Deputy Commandants as equity members as appropriate to the portfolio content; and with the CNR and the DASN RDT\&E as co-Executive Secretaries. This TOB will be responsible annually for the development of recommended priority lists of new-start projects for the BA-4 Transition program and, separately, a similar list for the BA-3 FNC program, for approval by the RDT\&E Corporate Board. The TOB will develop these recommendations with the assistance of IPTs, at the 2-star level, that should be established based on the thrust areas identified within the RDT\&E Strategic Plan. Annual initiation of new projects in both programs will be enabled by the annual release 
respectively of BA-4 and BA-3 funds by completing BA-4 and BA-3 projects. Consistency of purpose across the entirety of the RDT\&E portfolio is maintained within the proposed approach since (1) the RDT\&E Corporate Board defines the RDT\&E Strategic Plan and approves its subset, the S\&T Strategic Plan; (2) the RDT\&E Corporate Board charters and provides final approval for actions of the TOB, which develops a prioritized list of proposed BA-4 Transition projects and a similar prioritized list of proposed BA-3 FNC projects; and (3) the TOB is noted as including the senior members of the OPNAV and HQMC staffs responsible for Navy and USMC requirements definition and resource management, and who are also responsible for defining requirements for and providing funding for the follow-on BA-5 and BA-7 PORs executed within the PEOs. These same senior OPNAV and HQMC leaders are responsible as well for defining and resourcing the procurement of Navy and USMC materials and systems. The success or failure then of getting a technology through from inception to delivery as a Naval capability in this structure is governed precisely by the parties responsible for defining requirements and resourcing their deliveries to the warfighter. Senior military and civilian DON leaders will have clear visibility over, and a firm mandate for, defining and implementing the DON RDT\&E strategy, and for the first time, now with specific control over a DON-prioritized BA-4 portfolio.

This proposed structure then for the BA-4 Transition portfolio, and in parallel for the BA-3 FNC portfolio, is illustrated in Figure 9. Of particular note, management of the BA-4 and BA-3 programs is recommended to be performed by the DON SYSCOMs and by the ONR, respectively. This recommendation requires no change from the current management of the BA3 FNC program, but represents a significant change from the current management of BA-4 programs. It is consistent with Recommendation 2 in Chapter 2, is proposed for the reasons discussed in Chapter 2, and will be discussed further in this Chapter.

Figures 10 and 11, are included here to expand on Figure 9 by delineating the flow of BA-3 FNC and BA-4 project proposals starting from the definition of needs by the RDT\&E Corporate board, through to proposal development, to review and vetting of proposed efforts by the IPTs, to approval of a prospective prioritized portfolio by the TOB, and finally to approval of the portfolio by the RDT\&E Corporate Board. Figures 10 and 11 focus on the annual development cycle of proposals for new start projects, but also go further than Figure 9 in recognizing that while the RDT\&E Corporate Board will be approving the two portfolios, funding is left to be accomplished separately by the Navy and by the Marine Corps. Again, the steady-state of refreshing the two portfolios annually with new-start projects is dependent on completion, or termination, of prior approved projects. Initial achievement of this steady state condition will be discussed in Section 5.3.

For both the BA-4 and BA-3 FNC portfolios, the SYSCOMs and ONR should utilize and rely on the technical capability within the Navy Warfare Centers and/or Lab to work program execution jointly with industry, and at the very least to act as systems integrators in the BA-4 and BA-3 FNC programs. Such a utilization of in-house technical manpower is essential if the Federal Government is to have the capability to fully (1) refine requirements and specifications in advance of the next stage of development, (2) support critical evaluation and test of contractor efforts and deliverables, and (3) support a well-defined and truly open open-systems architecture (OA) approach to technology development and insertion. 


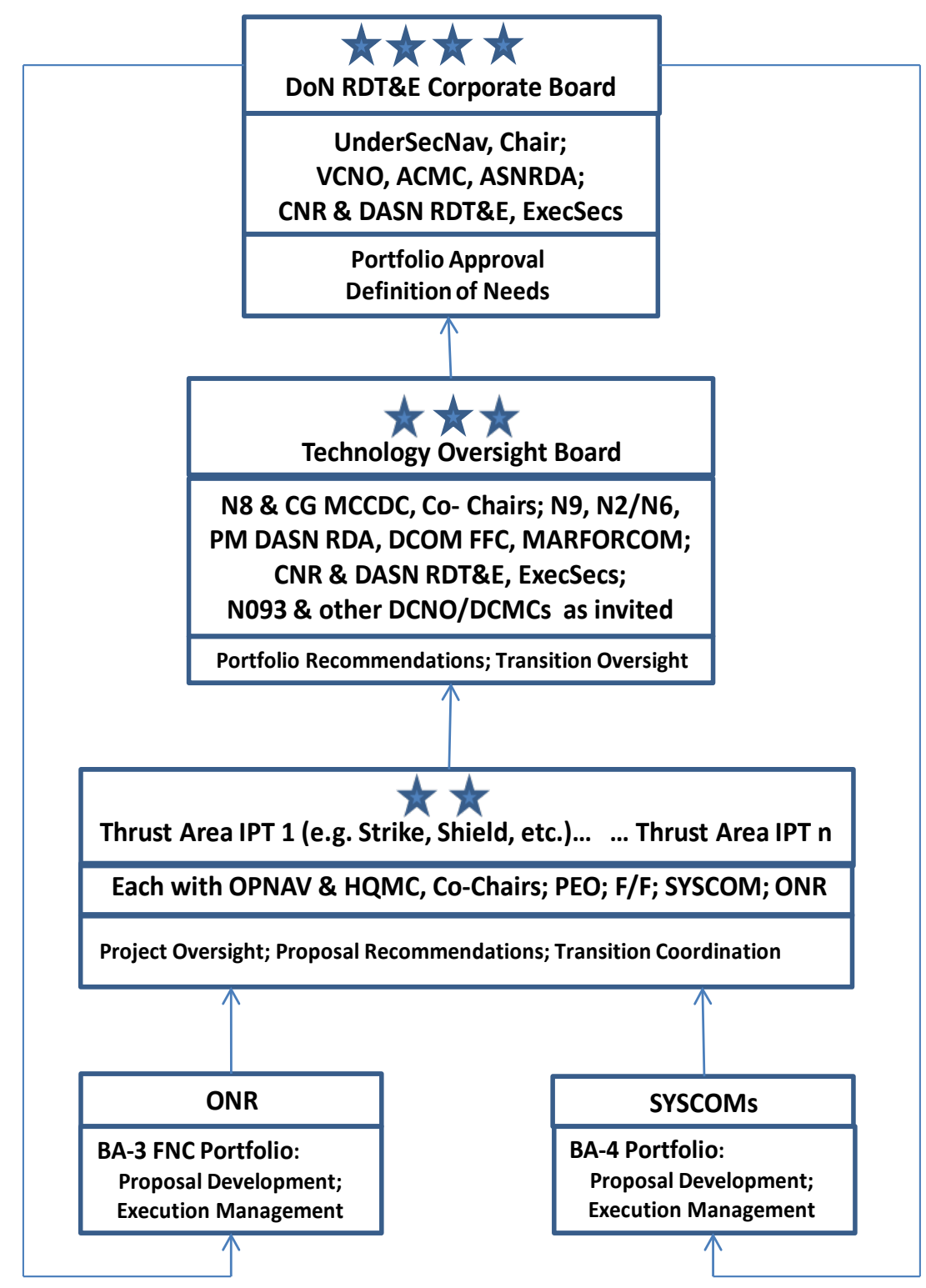

Figure 9: BA-4 and BA-3 FNC Management Process

The high-level flow for the development and approval of BA-3 FNC projects, and for their assembly into a prioritized program listing, is shown in Figure 10. As previously stated, it is slightly differently from that of Figure 9 in order to better illustrate the flow of proposal development, as opposed to the flow of authority shown in Figure 9. The proposed BA-3 FNC process, shown below, is modified only slightly from the current process, reflecting the introduction of the RDT\&E Corporate Board as the final approval authority for the BA-3 FNC program previously approved by the FNC Technology Oversight Group (TOG).

In this BA-3 FNC process, the RDT\&E Corporate Board approves S\&T gaps developed and proposed by the TOB based on the RDT\&E Strategic Plan and on the translation by the TOB of the directions from that plan into long-term perceived Naval capability gaps that could be addressed by S\&T. The Office of Naval Research then seeks out within the S\&T community 


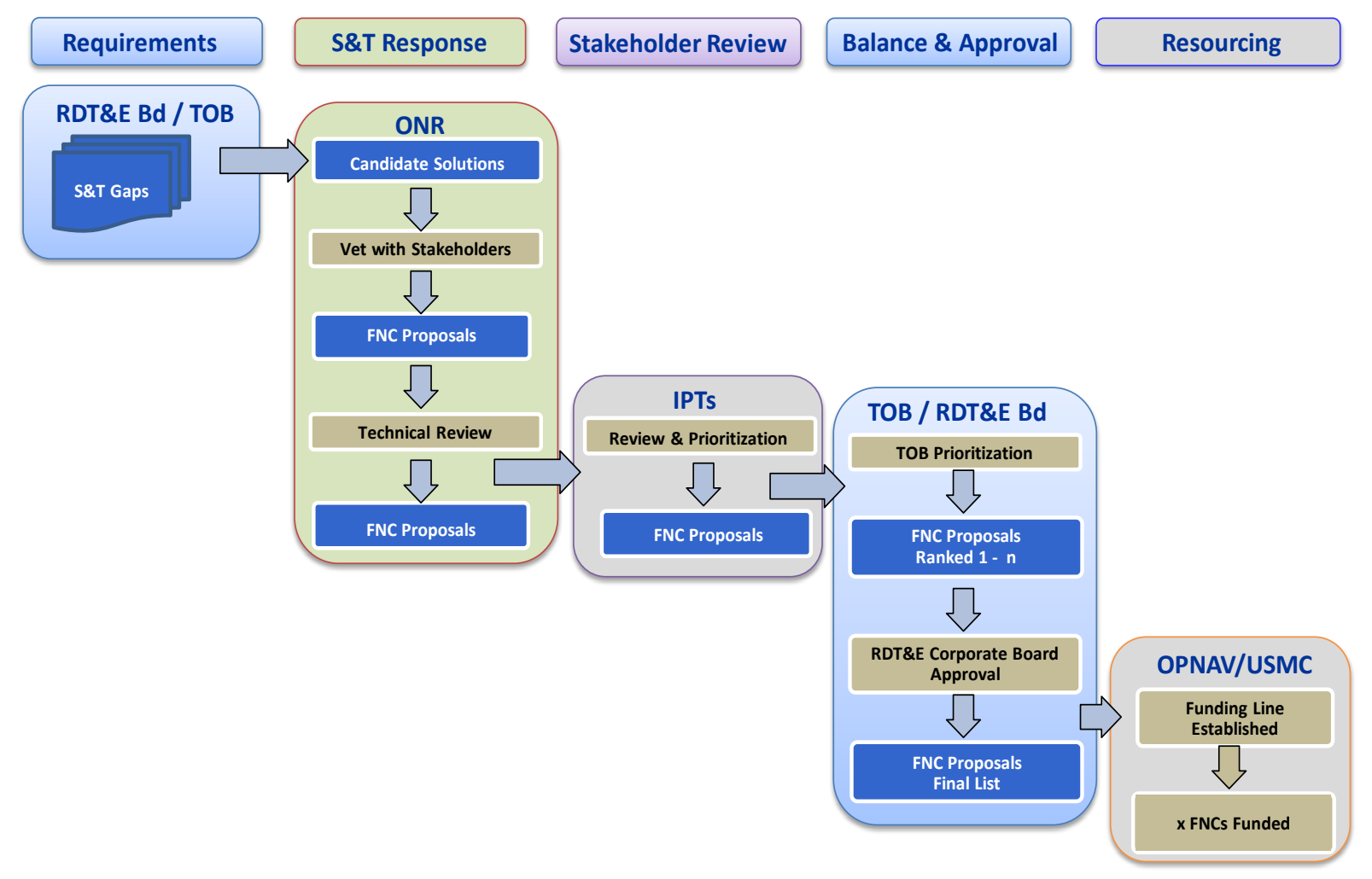

Figure 10: FNC Project Development Process

potential approaches to closing the capability gaps that can be proposed as FNC projects. These are vetted a priori with stakeholders and then provided to the RDT\&E IPTs for review, acceptance or rejection, and then prioritization. The TOB merges the prioritized lists from the various IPTs and provides a DON prioritized list for final approval by the RDT\&E Corporate Board. (Currently the TOG approves the project list subject to final review by the CNO and the CMC.) Funding is then provided, in the case of BA-3 FNCs through ONR, from Navy and USMC BA-3 funding lines. Funded projects are required to have TTAs signed by the S\&T lead, the appropriate PEO (or other transition target such as a BA-4 PM), and by the transition sponsor's OPNAV or HQMC resource and requirements sponsor(s). By statute, ONR has responsibility for execution management of S\&T within DON, but does so in the case of the FNC program, to the priorities set by the TOB, under authority of the RDT\&E Corporate Board, which also then annually reviews ongoing FNC projects for continuation based on satisfactory performance. The TOB is the arbiter of success for each FNC project at its completion, and again on behalf of the RDT\&E Corporate Board, the TOB subsequently tracks performance of FNC projects as they continue through the RDT\&E process. This latter tracking is done by means of an independent TRB, comprised of O-5 and O-6 Naval officers from the Naval Research Reserve. These officers track completed FNC projects (generally inserted in a BA-4, BA-5, or BA-7 program) through either to their final delivery to the fleet or force or until the technology is rejected for further pursuit by the acquisition community. The GAO (REF 4, p30) recommends this program tracking not only to measure immediate transition success, but also to evaluate "the longer-term impact of whether the technologies benefitted acquisition programs or military users 
in the field." They note also that (REF 4, p21) "leading commercial companies tracked technology transition not only to enable them to measure success, but also to assess their processes and determine what changes are necessary to improve transition rates.” DON is singled out in the GAO report as noteworthy in having implemented this tracking already in the FNC, Rapid Technology Transition (RTT), Technology Insertion to Produce Savings (TIPS), and Manufacturing Technology (ManTech) programs. Of note, more than 90 percent of all completed FNC projects have successfully transitioned, typically to a BA-4 program. Of those, in the long term, between half and two-thirds of the products have been or are on track to be delivered in quantity, to the fleet and/or force either separately or as part of a larger system.

A similar process is proposed for the BA-4 Transition portfolio but with a very critical and major difference. As in the case of the BA-3 FNC portfolio, any proposed BA-4 Transition project should be developed in response to Naval needs identified, broadly, in the RDT\&E Strategic Plan. Very much unlike the BA-3 FNCs, the responsibility for proposing and for execution management of these BA-4 projects, however, should not be vested at ONR. The ONR staff is and should remain focused on science and on exploring and maturing the art of the technologically possible in support of the DON mission. ONR S\&T programs should embrace and explore risk. The BA-4 Transition portfolio should be developed and managed rather by a Naval staff that has strong technical capability, but one that also has very strong roots in acquisition and on risk reduction and risk resolution. The focus needs to be not on exploration of the possible, but rather on operational experimentation with and then on demonstration of the realistically affordable and prospectively valuable. The PEOs most recently have had this responsibility but should not have it going forward. The reasons for this are developed more fully in Chapter 2 in the well-supported argument (see also REF 1, 6, 7, and 8) that the separation of technology development from product development is critical if we are to avoid costly overruns and schedule slips while also supporting quick reaction and speedy early delivery of new capabilities to the fleet and force. The PEOs are the DON product developers and should have product development and procurement as their primary focus, not technology risk reduction and early experimentation and demonstration. Indeed, from GAO (REF 1, p22), the "practice of accepting high levels of technology risk at the start of major weapon system acquisition programs ... is a major contributor to DOD's poor cost and schedule outcomes.” The separation of responsibilities of technology demonstration from product development has been shown to be critical to success in the high-tech business world (see also REF 1), and the DON is certainly a high-tech business, and more. The proposal and recommendation here then is that the DON Systems Commands be assigned the responsibility for the development of proposals for and then execution management of the BA-4 portfolio, and that they do so with their inherent close working awareness of the plans and technology needs for programs being executed or planned by the PEOs. The SYSCOMs work closely with and in a general sense host the PEOs. They supply much of the PEO Government technical workforce, either directly from within the SYSCOM or from a Naval Warfare Center or Lab, and they supply the technical authorities needed in most PEO acquisition/product development efforts. With support from their staffs and the Naval Warfare Centers, they are very well situated then to identify prospective BA-4 projects, some from Naval S\&T and some from elsewhere, that address the technology transition and in particular the speed-to-fleet/force, operational demonstration, and feasibility maturation needs of the DON. The SYSCOMs along with their technical authority expertise and with the Naval warfare centers and labs are ideally situated to manage and execute technology development and maturation, act when need be as the Federal Government integration agents for a major system 
prototype, conduct and evaluate experiments and operational demonstrations, provide sustainment and logistics support for fielded demonstration units, and partner as needed with industry in the BA-4 transition of technologies into proven capabilities ready for low-risk product development by a PEO. Figure 11 outlines the proposed BA-4 project proposal development, prioritization, and approval process.

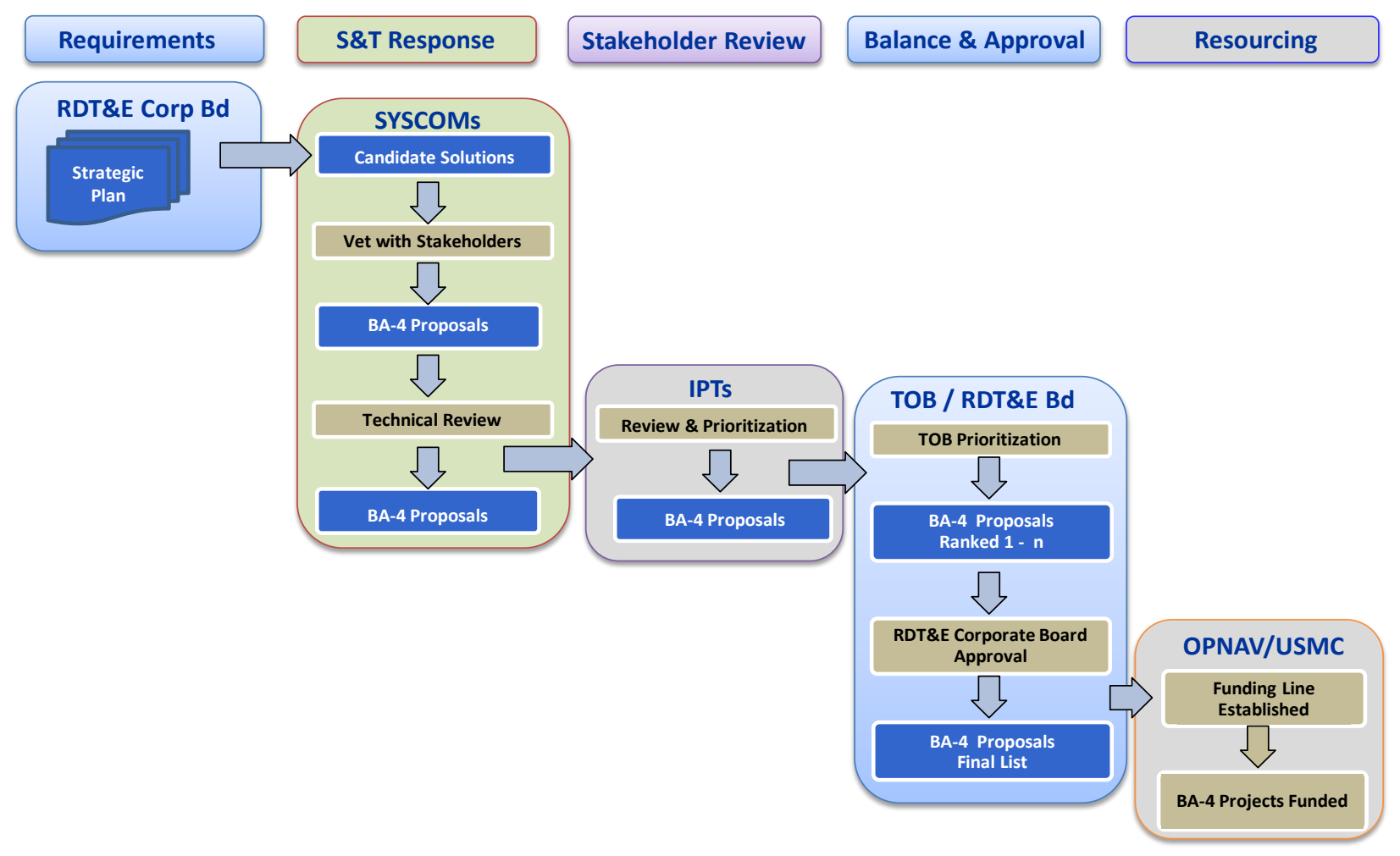

Figure 11: BA-4 Project Development Process

In this BA-4 process, the RDT\&E Corporate Board approves within the Naval Thrust Areas in the RDT\&E Strategic Plan a set of specific technology gaps and broad capability opportunities that defines the needs and directions for U.S. Naval force evolution. The Naval SYSCOMs then seek out within the R\&D community potential approaches addressing Naval capability gaps, or identifying opportunity innovations, that can be traced back to the RDT\&E Strategic Plan. These prospective proposals are vetted a priori with stakeholders and then proposals are provided to the RDT\&E IPTs for review, acceptance or rejection, and prioritization. The TOB merges the prioritized lists from the various IPTs and provides a DON prioritized list for final approval by the RDT\&E Corporate Board. Funding is then provided from Navy and USMC BA-4 funding lines to the SYSCOMs for execution of the approved projects in general with a Naval Warfare Center or Naval Lab acting as the Government integration agent working with industry. Funded projects are required to have TTAs signed by the SYSCOM (or designated Warfare Center or Lab) lead, the appropriate PEO (or other transition agent), and by the PEO's OPNAV or HQMC resource and requirements sponsor(s). The TOB will be the arbiter of success for each BA-4 project at its completion, and again on behalf of the RDT\&E Corporate Board, the TOB subsequently should track performance of BA-4 projects as they continue through the RDT\&E process to delivery to the fleet and/or force. This latter tracking can and should be done (see GAO recommendations [REF 4])) by means of an independent TRB, comprised of O-5 and O-6 
Naval officers from the Naval Research Reserve. These officers track currently completed FNC projects (generally inserted in a BA-4, BA-5, or BA-7 program) through either to their final delivery to the fleet or force or until the technology is rejected for further pursuit by the acquisition community. This existing team(s) can readily be assigned additional duties to track BA-4 projects subsequent to project completion. As in the case of BA-3 FNC projects, this tracking should be done through either to final delivery of the technology to the fleet or force or until it is rejected for further pursuit by the acquisition community. Repeating earlier comments, GAO (REF 4, p30) recommended this program tracking not only to measure immediate transition success but also to evaluate "the longer-term impact of whether the technologies benefitted acquisition programs or military users in the field." They note also that (REF 4, p21) "leading commercial companies tracked technology transition not only to enable them to measure success, but also to assess their processes and determine what changes are necessary to improve transition rates." Having a metric for the BA4 portfolio is something that should be of value to the DON.

The above figures and narrative refer to an IPT structure based on the Thrust Areas defined in the RDT\&E Strategic Plan. This prospective IPT structure will now be discussed. The intent is to provide, at the 2-star level, oversight management both for BA-4 and for BA-3 FNC projects that will incorporate the direct OPNAV/HQMC resource and requirements officials for each particular Thrust Area but also will include appropriate senior representation from within the fleet/force, PEO, and technical communities to enable a complete dialogue on the need, technical merits, and operational viability and value of each technology-enabled capability. The current BA-3 FNC IPTs have five members. The proposed IPT structure, with the addition of a SYSCOM representative, has six members for both BA-4 as well as BA-3 FNC oversight:

- OPNAV and HQMC Co-Chairs,

- Warfighting, senior staff from FFC and/or MARFORCOM,

- Product Development, a PEO or DASN,

- R\&D, a SYSCOM Department Head,

- S\&T, an ONR Department Head.

It is presumed that subject to RDT\&E Corporate Board approval, the IPT members would be appointed by the TOB as follows:

- OPNAV and HQMC Co-Chairs - by the TOB Co-Chairs (N8 and CG MCCDC),

- Warfighting, staff from Fleet or Force - by the DCOM FFC and by MARFORCOM,

- Product Development, a PEO - by PM DASN RDA,

- R\&D, a SYSCOM Department Head - by the Commander of the SYSCOM identified by PM DASN RDA as the lead SYSCOM for the Thrust Area,

- S\&T, an ONR Department Head - by the CNR.

If the RDT\&E Corporate Board were to use the prospective thrust areas offered as an example in Chapter 4, then there would be nine IPTs:

- Sea Shield - Missile defense, ASW, MCM, and fleet/force protection technologies global defensive assurance 
- Sea Strike - Weapons, aircraft, and expeditionary warfare technologies - precise and persistent offensive power

- Sea Basing - Logistics, shipping, and at-sea transfer - operational independence

- $\quad$ ForceNet - C4ISR, networking, navigation, decision support, and space technologies architectural framework for Naval warfare in the information age

- Naval Expeditionary Maneuver Warfare - Warfighting capabilities of Naval ground forces, with special emphasis on regular and irregular warfare

- Capable Manpower - Matching sailors and marines to the right jobs, designing intuitive systems, and training for mission essential competencies

- Force Health Protection - Protecting sailors and marines and reducing morbidity and mortality when casualties occur

- Enterprise and Platform Enablers - Cross-cutting technologies to lower acquisition, operations, and maintenance costs

- Power and Energy - Energy security, efficient power and energy systems, high energy and pulse power

The membership as an example for the Sea Strike IPT might include OPNAV N98 and HQMC Aviation as co-chairs, USFF N8, PEO Unmanned Aviation and Strike Weapons (U\&W), a Naval Air Systems Command (NAVAIR) Department Head, and an ONR Department Head (likely Code 35). Where multiple codes within an organization may claim some equity interest, the TOB appointing official might consider rotating membership annually or biennially, in this example say between PEO U\&W and PEO Tactical Air Programs (T). The expectation and the charge from the TOB, however, should be that each IPT representative act on behalf of their TOB senior and not parochially for their own specific organization.

Recommendation 5: The RDT\&E Corporate Board should assign management of and proposal development for the DON BA-4 portfolio to the DON Systems Commands, with execution through a Naval Lab or Warfare Center, and with intermediate management oversight by a 3-star Technology Oversight Board (TOB) with a 2-star IPT support structure based on the thrust areas defined within the RDT\&E Strategic Plan.

Recommendation 6: The RDT\&E Corporate Board, through the TOB, should track success or failure of completing BA-4 and BA-3 FNC projects based on IPT assessments and should track completed projects through to final product delivery using an independent, appointed, Technology Review Board (TRB).

In Section 5.1, the proposed role for a separately managed BA-4 portfolio was discussed at length. The four identified roles warrant some further discussion in light of the proposed management structure laid out above for the BA-4 portfolio, and a critical "housekeeping" function needs to be introduced as well. The housekeeping function is shown in Figure 12, in the overlapping oval, as "SYSCOM Seams" and "BA-4 Jump Start." Both of these are critical to the success of the proposed BA-4 Portfolio.

The "SYSCOM Seams" categorization is a recognition of the fact that the SYSCOMs, and some other organizations such as Navy Warfare Development Command (NWDC), already have 
access to a limited amount of BA-4 funding to cover experimenting and prototyping functions and activities including, for example, needs and requirements that do not fall clearly within the purview of any of the PEOs that they host. Hearing protection, as pursued at NAVAIR, is an example of a seam topic that cuts across multiple PEOs and that has been addressed by the SYSCOM with BA-4 funding, and with prototype products provided for further development to multiple PEOs. These seam issues will continue to exist and warrant attention and funding within the DON. The RDT\&E Corporate Board through the TOB should annually review the efforts conducted by the SYSCOMs to verify continued value to DON and then can adjust the seam funding provided to each SYSCOM.

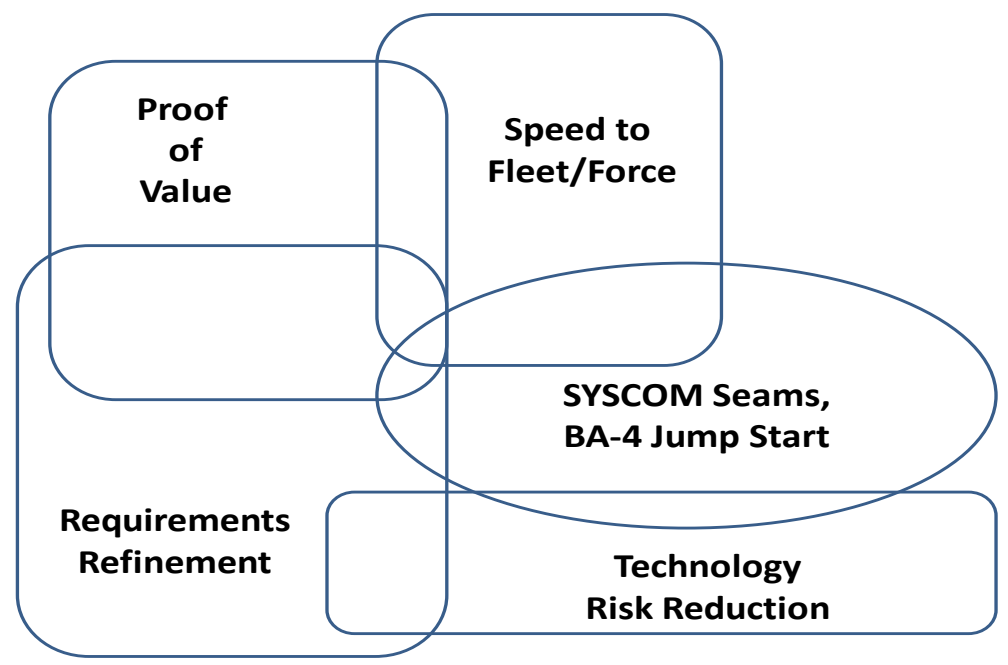

Figure 12: BA-4 Portfolio

The BA-4 "Jump Start" categorization is a bit more complex. Consider the likely timeline of a new BA-4 project. Based on the needs and direction defined in the RDT\&E Strategic Plan, proposals are developed by a SYSCOM, with preliminary vetting with prospective transition partners, and are then submitted to the BA-4 TOB say in late FY X-1. The TOB, with the subordinate IPTs, reviews and prioritizes the multiple proposals in early FY X and submits a portfolio for RDT\&E Corporate Board approval in the second quarter of FY X for insertion in the late second or early third quarter into the DON FY X+2 budget. An approved project by this process then does not get funded until more than 2 years after initial submission - not a speedy path to the fleet and/or force. In the BA-3 FNC process, the delay is cut in half to allow project initiation, at a reduced level, in the FY immediately following project approval, that is, in FY $\mathrm{X}+1$. To support this in the BA-3 FNC program, funds are set aside in the ONR FY X+1 budget (and for BA-4, similarly should be budgeted for each of the SYSCOMs) and are then distributed in FY $\mathrm{X}+1$ as needed to "jump start" the newly approved projects. During the now only 1-year delay, congressional staff is apprised of the approval by DON leadership of the "new starts" that will be initiated (jump-started) in the next FY (FY X+1) and that will appear in the DON budget submission for FY X+2. The staffers have recognized that for the BA-3 FNC program the new start projects represent a continuation of prior S\&T investments and the staffers have accepted the jump-start funding of these continuing RDT\&E efforts as not representing a legally defined new start during a continuing resolution. They do expect that the new projects will be identified 
in the subsequent DON budget submission, but they have come to recognize and appreciate the "jump start" process as a way of speeding the insertion of new technologies to the warfighter. Identification of jump-start funding for newly approved BA-3 FNC projects then has proven both to be necessary and quite defendable within DON, OSD, and Congress. Setting aside a fraction of the DON BA-4 funding to support a similar jump-start process for the BA-4 portfolio is highly recommended.

In Figure 12, the categories "Requirements Refinement," “Technology Risk Reduction,” and a large fraction of "Proof of Value" can be considered as directly supporting either ongoing or planned PORs. These categories are well understood and are familiar from within the current DON RDT\&E BA-4 program. A significant part of the Proof of Value categorization, however, should be considered as being associated with experiments and demonstrations that, to paraphrase Under Secretary Kendall (REF 15), are of critical capability interest to DON but are acknowledged to having as yet no planned follow-on procurement. This latter part of the Proof of Value categorization includes demonstration of capabilities for which DON has a need but, in a severely budget constrained situation does not yet choose to produce in quantity. Demonstration of these types of capabilities allows development to have been completed sufficiently that a capability can be put "on the shelf" with the knowledge that a demonstrated capability is available for quick procurement should world events warrant an immediate need. Another part of the Proof of Value category, though, is proposed to be reserved to address those innovative new approaches to Naval warfare that may initially seem too radical or far-fetched to engender sufficient support for developing a POR, at least until after full demonstration of the capability in an operational environment. These could include shipboard demonstration of an electro-magnetic rail gun, or a free-electron laser, or perhaps a very long endurance unmanned underwater vehicles (UUV) capable of being launched from Guam or Japan and supplanting attack subs in doing autonomous patrol and surveillance functions in some areas of the far western Pacific. There is little current ability on the part of the SECNAV, CNO, or CMC today to rapidly initiate a significant innovation without either having to defund some ongoing effort(s) or otherwise having to hand a bill to someone, for example in the case of the UUV, to OPNAV N97 for initiation of the directed new program in the next budget cycle. This represents either serious disruption to a POR for the former or a delay in initiation by minimally 2 years for the latter. The proposed BA-4 bidding process will support initiation in the FY following program approval by DON leaders, and will not cause ongoing projects to be de-funded in order to initiate the new effort.

In Chapter 4, a recommendation was made that the DON develop an RDT\&E Strategic Plan that includes within it a specific commitment to a balance across the RDT\&E accounts such as that shown in Figure 7. It is suggested that serious consideration also be given to codifying within the RDT\&E Strategic Plan a delineation of the constituent parts of the proposed BA-4 portfolio as defined above, and as shown in Figure 12, and that minimum investment floors be set for each of the categories in order, at the DON level, to prevent the exigencies of the day from robbing the future. A prospective starting point is provided as follows:

- Speed to Fleet/Force > 20 percent

- Seams/Jump Start $\quad>10$ percent 
- POR Support

$>40$ percent

- Risk Reduction

- Technology Risk reduction

- Part of Proof of Value

- Innovation

$>20$ percent

- Part of Proof of Value.

This model leaves 10 percent of the BA-4 account for annual adjustment by the RDT\&E Corporate Board across the boundaries of the four categories. With this, in a given year speed to fleet/force, for example, could be as much as 30 percent of an upcoming BA-4 budget if the RDT\&E Corporate Board saw the demand signals as warranting this much of an investment.

Recommendation 7: Within the RDT\&E Strategic Plan, explicitly recognize the BA-4 Portfolio as consisting of (a) Speed to Fleet/Force; (b) SYSCOM Seams and BA-4 Jump-Start; (c) Proof of Value, including specifically a significant Innovations investment; (d) Requirements Refinement; and (e) Technology Risk reduction. Identification should be made of minimum budgeting goals for each category.

The BA-4 management and control described in this section aligns the BA-4 portfolio with the Naval mission and with future Naval capability needs by means of a BA-4 project selection process that explicitly follows needs set forth by senior leadership, the RDT\&E Corporate Board, and that funds specific new BA-4 projects subject to an annual prioritization selection process run by that Board. This process enables and requires senior leaders to identify and implement a strategic vision for the future of the DON. Consistent with earlier recommendations, the new approach also provides for BA-4 project management separate from but closely aligned to the DON product developers, enabling the PEOs to focus solely on product development of affordable and valuable Naval products.

The presumption above is that, within the BA-4 portfolio, there will be an annual refresh cycle using funds released by the completion of existing BA-4 projects to enable initiation of Boardapproved new BA-4 projects. Initiation and sustainment of that annual refresh process will be discussed in the next section.

\subsection{Definition of a "Roll-in" Period for the new BA-4 Portfolio}

The BA-4 portfolio management structure proposed above is portrayed in a steady state condition with the entire BA-4 budget under the direct management of the RDT\&E Corporate Board/TOB/IPTs. There is presumption of a regular completion of approved BA-4 projects leading to funding being available annually for new start proposals to be developed, evaluated, prioritized, and (some) approved by the RDT\&E Corporate Board for funding. Unfortunately, this steady state condition currently does not exist, the abrupt initiation of it would be very difficult to develop, and the impact on existing programs of an abrupt shift of funding to a new portfolio should be expected to be severe. With some planning however, the desired portfolio management structure should be able to be "rolled-in" over a 3 to 4 year period with minimal undue impact on existing programs. Of particular note, the regular completion of BA-4 projects 
is occurring under the current governance process; this already existing regularity of completions offers the opportunity to phase in the new BA-4 portfolio management structure without causing undue harm to existing programs. Under the auspices of the DASN RDT\&E, the DON has already completed an initial review of ongoing BA-4 projects. This review should be expanded, by direction of the RDT\&E Corporate Board, to develop a "waterfall" chart for all ongoing BA-4 projects, identifying products under development, and showing for each a timeline with major milestones, product deliveries, and completion. This timeline will reveal product deliveries throughout the FYDP, and in many if not most cases, follow-on new product initiations under the auspices of the same resource office. This waterfall timeline then enables the TOB, acting on behalf of the RDT\&E Corporate Board, to decree that as of some point, FY X, any new starts will be subject to the new BA-4 portfolio ground rules defined in Section 5.2 and that the funding planned previously for any new starts is under the control of the TOB as of FY X. Figure 13 illustrates this for a sample BA-4 DON budget of $\$ 500$ per year. In this example, there are three major programs: A, B, and C. The total of BA-4 funds available in aggregate is $\$ 500$. Each Program has been given a budget based on prior submitted plans, and each plans out future projects recognizing that any increase in own funds will come at the expense of another Program and that gains in funding for other Programs are likewise subject to the same zero sum constraint within the BA-4 Portfolio. Program A has 4 projects either underway or planned for the FYDP. Project A.1 is completing in FY X-1; A.2 is continuing; A.3 is planned to start in FY X; and A.4 is planned for an FY $\mathrm{X}+3$ start. The overall budget is balanced and stable.

The total budget shown here for BA-4 is presumed to be stable at $\$ 500$ per year for the time period shown. Under the current planning as shown, there is no funding apparently available for new starts, since each Program is shown as requiring flat/stable funding throughout the FY X-1 to FY X+4 period (i.e., throughout the FYDP). If the TOB, after careful collection of specific planning for each BA-4 Program, defines that no new starts within Programs will be allowed effective with FY X, then the Projects shown in red in Figure 13 represent funds available to the RDT\&E Corporate Board/TOB/IPTs to allocate to BA-4 new starts using the strategic planning process outlined in Section 5.2. In this example, there is no early termination of any ongoing project, and any of the new starts shown under the prior planning system can be bid, via a SYSCOM, under the new process for review, recommendation, prioritization, and funding by the RDT\&E Corporate Board/TOB/IPTs. If the prior-planned-project valuation is sufficient, it will be funded as before. If there are higher priority projects identified as part of the new and broader DON overview process, then the higher priority projects will be funded instead. Regardless of which projects get funded, those projects that get selected will be funded in accordance with DON strategic planning, will have been accepted and prioritized by senior leadership, and will meet one of the proposed prescribed roles of BA-4 programs: speed to fleet/force, proof of value to the warfighter, requirements/specification refinement prior to POR initiation, or risk reduction of technologies prior to introduction into a POR.

A similar process should also be considered for any adjustments in funding levels amongst BAs $4,-5$, and -7 so as to avoid unwarranted disruptions to continuing programs.

Given the lead time for development of the RDT\&E Strategic Plan and allowing for a reasonable lead time for the SYSCOMs, with support from the Naval Warfare Centers and Labs, to develop proposed efforts addressing the needs set forth in the Strategic Plan, consideration should be given to establishing FY X as being 2 years out, FY16. For as quick a roll-out of the proposed new BA-4 project selection process as this may seem, there is every opportunity for a soft start to 


\begin{tabular}{|c|c|c|c|c|c|c|c|}
\hline \multirow{5}{*}{$\begin{array}{c}\text { Program A } \\
\$ 125\end{array}$} & & & & & & & \\
\hline & Project A.1 & $\$ 50$ & & & & & \\
\hline & Project A.2 & $\$ 75$ & $\$ 80$ & $\$ 70$ & $\$ 30$ & & \\
\hline & Project A.3 & & $\$ 45$ & $\$ 55$ & $\$ 95$ & $\$ 95$ & $\$ 90$ \\
\hline & Project A.4 & & & & & $\$ 30$ & $\$ 35$ \\
\hline \multirow{4}{*}{$\begin{array}{c}\text { Program B } \\
\$ 175\end{array}$} & & & & & & & \\
\hline & Project B.1 & $\$ 175$ & $\$ 175$ & $\$ 175$ & $\$ 100$ & $\$ 50$ & \\
\hline & Project B.2 & & & & $\$ 75$ & $\$ 125$ & $\$ 125$ \\
\hline & Project B.3 & & & & & & $\$ 50$ \\
\hline \multirow{5}{*}{$\begin{array}{c}\text { Program C } \\
\$ 200\end{array}$} & & & & & & & \\
\hline & Project C.1 & $\$ 90$ & $\$ 60$ & & & & \\
\hline & Project C.2 & $\$ 110$ & $\$ 140$ & $\$ 120$ & $\$ 80$ & & \\
\hline & \begin{tabular}{|l|} 
Project C.2 \\
\end{tabular} & & & $\$ 80$ & $\$ 80$ & $\$ 100$ & $\$ 80$ \\
\hline & Project C.4 & & & & $\$ 40$ & $\$ 100$ & $\$ 120$ \\
\hline \multirow[t]{2}{*}{ TOTAL \$ } & & $\$ 500$ & $\$ 500$ & $\$ 500$ & $\$ 500$ & $\$ 500$ & $\$ 500$ \\
\hline & & FY X-1 & FY X & FY X+1 & FY X+2 & FY X+3 & FY X+4 \\
\hline \multicolumn{2}{|c|}{ AVAILABLE WEDGE \$ } & \$0 & $\$ 45$ & $\$ 135$ & $\$ 290$ & $\$ 450$ & $\$ 500$ \\
\hline
\end{tabular}

Figure 13. BA-4 Waterfall Chart

the process by the simple expedient of having the SYSCOMs consider many of the already planned new efforts as being likely candidates for their initial submissions to the new BA-4 process. The presumption is that the individual resource sponsors and PEOs properly have identified legitimate DON needs that they are addressing, so these should be considered as candidates for early proposals. The deeper presumption, however, is that any delay from a quick start will be further delay in allowing senior leadership to have specific visibility into setting the direction of the DON capability development process, and will introduce further delay into giving that leadership the greater flexibility needed to address speed to fleet/force and other issues demanding leadership attention and action.

\subsection{Proposed Structure and Governance Process for the BA 5 \& 7 Portfolios}

In this section, two more parts of the overall RDT\&E portfolio, comprising the product development phase (BAs 5 \& 7) illustrated in Figure 14, will be considered and recommendations provided.

\begin{tabular}{|c|c|c|c|c|}
\hline \multirow{2}{*}{$\begin{array}{l}\text { Strategic } \\
\text { Planning }\end{array}$} & \multicolumn{3}{|c|}{ Technology Development } & \multirow{2}{*}{ Product Development } \\
\cline { 2 - 4 } & Explore & Develop & TRANSITION & \\
\hline & BA 1\&2 & BA 3 & BA 4 & BA 5\&7
\end{tabular}

Figure 14: Process Flow for Technology Insertion 
MDAPs within DON already are subject to significant senior leadership oversight and review. The SECNAV Charter for the RDT\&E Corporate Board, however, would seem to warrant at least a periodic, critical review by the Corporate Board to include all of RDT\&E if the Board is to (REF 16, para 4.a) "Provide recommendations on strategic issues and policy changes to the Secretary of the Navy, the Chief of Naval Operations (CNO), and the Commandant of the Marine Corps (CMC) to ensure alignment between selected technologies and Naval needs." Such a review, including MDAPs, will enable the Board to establish an overall context of the Naval RDT\&E program. But, if it is to form the basis for "strategic oversight and monitoring of the Department of the Navy's (DON) RDT\&E investments and activities of RDT\&E (6.1-6.7) portfolios, programs, and priorities," (REF 16, para 2) the Board should use the review to provide recommendations on continuation, modification, or termination of ongoing programs and on start-up of proposed new programs, with priorities assigned based on relative value to DON. This review should assess, and as need be enforce, commitments for hand-over from Transition (BA-4) to Product Development (BA-5 or BA-7). It could also consider whether the various Product Development programs are properly binned - CEC, for example, likely is a better candidate after 20 or so years of development for labeling as a BA-7 program rather than BA-5. More importantly perhaps, there are a significant number of non-MDAPs within the BA-5 and BA-7 portfolios that do not get the same level of senior oversight provided to MDAPs. A review, including all of the BA-5 and -7 programs, will provide an opportunity for a reevaluation of and recommended adjustment of priorities across warfare community boundaries. Moreover, as the overall budget of DON can be expected to continue to be stressed, it would appear to be critical that the Board identify a DON prioritization of the needs of DON and that this be reflected in the BA-5 and BA-7 programs.

Recommendation 8: The RDT\&E Corporate Board, through the Transition Oversight Board and subordinate IPTs, should conduct an annual or biennial review and critical assessment of all ongoing and proposed new BA-5 and BA -7 programs.

The ever-worsening budget crisis will drive DON to make increasingly difficult choices, and a unified management structure based on senior-leader-defined strategic vision and establishing senior-leader-defined investment priorities is arguably the best approach to making those very difficult choices across a disparate group of warfare interests (air, land, surface, and undersea) and in an environment where trade-offs will need to be made among the demands of ongoing and planned acquisition programs.

\subsection{Proposed Governance Structure for the BA6 Portfolio}

The final piece of the RDT\&E Portfolio is the BA-6 account. The BA-6 portfolio includes T\&E support both for infrastructure as well as manpower, including that for S\&T management. A review by the RDT\&E Corporate Board of this portfolio should address the long-term adequacy of the DON T\&E program and infrastructure. In addition, it should consider the appropriateness of having some of S\&T management salaries within the BA-6 portfolio as opposed to being moved, with the funding, into the S\&T accounts for better visibility and oversight. Given that the BA-6 role is an overarching one, it may be appropriate for the RDT\&E Corporate Board to establish an overarching IPT to assess the BA-6 portfolio and provide policy, structural, and 
budgetary recommendations to the Board. A prospective IPT membership might be DASN RDT\&E, OPNAV N84, and ACMC (MCOTEA). 


\section{Implementation Discussion}

If a decision is made to adopt the recommendations herein, there are several implementation issues that will need to be addressed early on. There are also related items, including one legislative matter, that should be considered that could help in the implementation. These will be discussed in this chapter, with an underlying assumption that the recommendations have been accepted.

Before proceeding with the discussion of how the recommendations herein can be implemented, it is worth noting that there appears to be no requirement for any changes to be made to SECNAVINST 5000.2. BA-4 funding is quite legally available for Early Experimentation and Demonstration in support of Speed-to-Fleet/Force and to support Proof of Value, that is, warfighter buy-in on new capabilities; for Requirements/Specifications Refinement prior to POR initiation; and for Risk Reduction for technologies prior to their introduction into a POR.

While there is no requirement to make any changes to SECNAVINST 5000.2, if the recommendations herein are to be adopted, there does appear to be the need for changes to the Charter for the Naval RDT\&E Corporate Board. The MISSION statement in the Charter certainly can be construed as providing the Board with the scope to implement the recommendations in this paper. The RESPONSIBILITIES statement, however, begins as follows: "The RDT\&E Corporate Board will establish and maintain a coordinated and comprehensive RDT\&E program to meet Naval goals and objectives.” However, then this very broad and serious charge is followed by a specific listing of responsibilities that could be construed as restrictive and that may need to be expanded if the Corporate Board is to have the oversight and monitoring authority over the DON RDT\&E portfolio to the level recommended herein. It would appear that the actions recommended in this paper could be enabled with a few simple (but substantive) changes to section 4.b of the Charter:

1. Oversight of the Naval RDT\&E Strategic Plan (no change)

2. Approval of DON BA-4 Portfolio (an annual process to be managed by the three-star TOG and executed by the DON SYSCOMs) (new)

3. Approval of the Naval S\&T Strategic Plan (no change)

4. Approval for Innovative Naval Prototypes (no change)

5. Approval of Future Naval Capabilities Portfolio (FNC - an annual process managed by the three-star TOG and executed by the ONR) (minor change to be consistent with 4.b(2))

An alternative to modification of the Charter is to implement the recommendations in the Naval RDT\&E Strategic Plan and have that Plan released over the signature of SECNAV.

On the other hand, if the "Oversight of the Naval RDT\&E Strategic Plan" widely is considered implicitly to include management oversight of the Naval RDT\&E Portfolio, then no change is needed in the Charter and the Board has sufficient authority on its own to implement all of the recommendations in this paper, if it so chooses.

A Charter for the Transition Oversight Board separately should be developed and signed out by the RDT\&E Corporate Board. This can readily be done as an expansion to the current FNC TOG 
Charter previously signed out by the S\&T Corporate Board, at which point the name could be changed to Technology Oversight Board, if so desired. This document can identify the processes and the bidding and execution management roles of the SYSCOMs and of ONR, respectively for the BA-4 Portfolio and the BA-3 FNC program. The document should also focus on the RDT\&E thrust areas defined in the RDT\&E Strategic Plan and use them as the basis for the establishment under the TOB (TOG) of the subsidiary IPTs, which in turn would need to be chartered. The likely need is recalled for possibly two additional non-thrust-area IPTs to provide oversight for BA-4 Innovations and SYSCOM Seams/Jump Start.

The rather core Recommendation \#1 (Chapter 2) to require acquisition programs to be initiated with no critical technology elements (CTE) having less than a TRL 7 would appear to be within the purview of the DON Service Acquisition Executive. Implementation of this recommendation could be introduced by a memo from ASN RDA. Introduction via a memo would allow the ASN RDA to identify opportunity for exceptions, such as for planned programs where the change in rules otherwise would introduce significant delays or re-scoping of the effort. A memo introduction would also allow for better evaluation and correction of any unintended consequences. It could also specify a phase-in period for the implementation.

As a minor legal issue, a legislative change proposal was requested by the DON in FY08 and again in FY09 that was passed into law as Section 819 of the FY10 NDAA (REF 18). This law allows the addition of limited BA-4 funds to an S\&T contract that was started with a Broad Agency Announcement (BAA), thus allowing for immediate BA-4 transition of technology from the S\&T community without need for a lengthy new contract competition. Use of this mechanism could be useful in speeding up initiation of BA-4 speed-to-fleet/force demonstrations that are based on ongoing S\&T efforts and should be considered for more extensive use if the new BA-4 governance process is adopted. As it was passed, the law sunsets on September 30, 2014, and, if not already done, consideration should be given to requesting an extension/renewal.

As final point in the discussion of implementation of the proposed changes to the DON RDT\&E governance, the related roles of the various players will be summarized, with current related roles and proposed changes noted:

- Naval RDT\&E Corporate Board

- Currently: Recommendations of strategic issues and policies; Oversight of the Naval RDT\&E Strategic Plan; Biennial Approval of the Naval S\&T Strategic Plan; Biennial Approval of INPs; Annual Review of TOGapproved FNCs; Oversight of study groups and FOBs reviewing RDT\&E applications, strategy, and investments; Assist in developing policies for rapid S\&T project transition into PORs. Charter the TOG

- Proposed Change: Add - Annual Approval of BA-4 Portfolio plan recommended by TOB(TOG); Add - Annual Approval of FNCs as recommended by the TOB(TOG); Add - Re-Charter the TOB (TOG) to include BA-4.

- $\quad$ TOB (TOG) and Subordinate IPTs

- Currently: Annually approve new FNCs, and confirm ongoing FNCs; Charter the FNC IPTs. 
- Proposed Change: Add - Develop prioritized plan for new BA-4 projects; Add - Confirm priority of ongoing BA-4 projects; Add - Develop prioritized plan for new FNCs; Add - Confirm priority of ongoing FNCs; Add - Re-Charter the IPTs to include BA-4 and FNC projects.

- PEOs

- Currently: Manage Execution of BA-4 projects and of BA-5 and BA-7 PORs.

- Proposed Change: Delete - BA-4 management and execution responsibility.

- SYSCOMs

- Currently: Provide infrastructure support for PEOs; Manage WCs; Manage Execution of BA-4 projects.

- Proposed Change: Add - Initiate Bids for new BA-4 projects; Add - BA-4 management and execution responsibility.

- ONR

- Currently: Manage Execution of DON S\&T Program; Initiate Bids for new INPs and new FNCs.

- Proposed Change: none

- DASN RDT\&E

- Currently: Broad Oversight of DON RDT\&E Portfolio; Co-Executive Secretary of Naval RDT\&E Corporate Board

- Proposed Change: Add - Responsible within OASN RDA for DON BA-4 Portfolio; Add - Coordinate technology transfer to Product Developers.

- CNR

- Currently: Responsible for the DON S\&T Program; Co-Executive Secretary of Naval RDT\&E Corporate Board; Member of TOG; Coordinate Naval S\&T Strategic Plan; Dual-hatted as N84 - TOG Executive Secretary and Resource Sponsor for N8 S\&T.

- Proposed New: Add - Dual-hatted within N84 as Resource Sponsor for Navy S\&T; Dual-hatted within DC CD\&I as Resource Sponsor for USMC S\&T.

Most of the proposed changes in the above listing have been discussed previously in this report. The final proposed change has not. It has been included strictly for symmetry. The CNR by statute is a direct report to the Secretary of the Navy, with administrative reporting through ASN RDA. The CNR by that same statute has responsibility for the management of all DON S\&T. He (or she) by more recent statute is a two-star Flag Officer in the U.S. Navy at least for the term of office as CNR (if not otherwise confirmed in that rank). More recent CNRs have been dualhatted as N8 S\&T Resource Sponsor. The change consolidates the small balance of Navy S\&T resources, not under control of N84, under a single sponsor organization and includes a 
comparable responsibility within the USMC HQ staff. The symmetry allows for a direct line of responsibility and accountability by the CNR for the conduct of all Naval S\&T to the Secretary of the Navy, through ASN RDA; as CNR to the Naval RDT\&E Corporate Board; and as the dual-hatted S\&T Resource Sponsor to the two service chiefs, the CNO and the CMC. 


\section{Conclusions}

The fundamental goal of the DON RDT\&E program is to identify, develop and maintain the capabilities of our Naval warfighters as notably the most advanced in the world. In this paper, we have considered that Research, Development, Test, and Evaluation (RDT\&E) program holistically. The underlying premise has been that DON is not doing a good enough job of strategically managing its RDT\&E portfolio and that, at least partly as a result, DON is spending too much and taking too long in getting new technology-driven capabilities into the hands of our warfighters. The assertion has been made that DON (and indeed all of DOD) R\&D has become too prototype averse, and that S\&T has become too risk averse. The paper has asserted that this state is nearly perfectly opposite from where the DON should be operating. This current state is symptomatic of not having a strategic plan. Process, and perhaps more importantly, cultural change is needed and have been proposed herein.

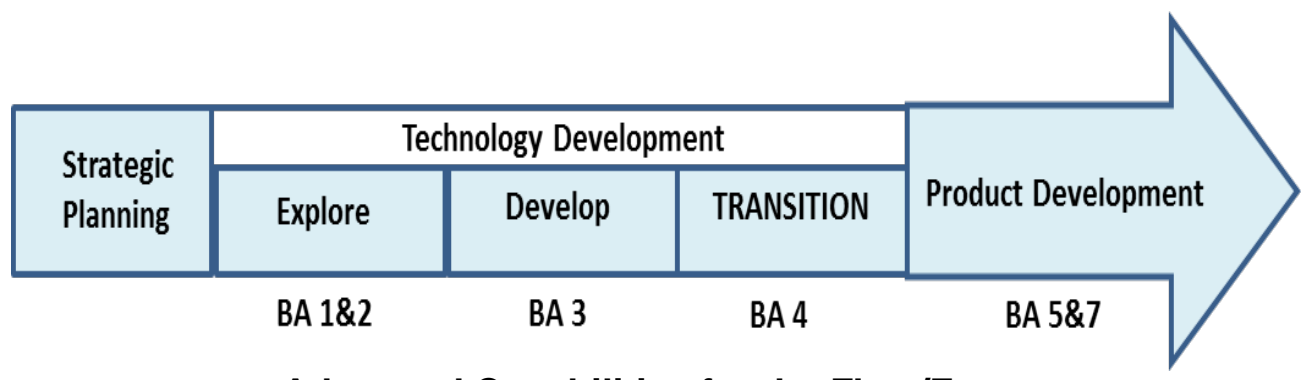

Advanced Capabilities for the Fleet/Force

Figure 15: Process Flow for Technology Insertion

As illustrated in Figure 15, the length and breadth of the RDT\&E process has been explored, from Strategic Planning; through the Technology Explore (BA-1 and BA-2), Develop (BA-3), and Transition (BA-4) phases; and to the Product Development (BA-5 and BA-7) phase from which emerges weapons and systems that enable advanced capabilities for our fleet and force. While much of the focus of the paper has been on the technology development phases of RDT\&E, recommendations have been made that address a fundamental and strategic re-forming of the entire DON RDT\&E process.

In these challenging times, it is posited that now more perhaps than in a long time that senior leadership of DON has incumbent upon it a compelling need to identify their strategic vision for a dominant future fleet and force, to identify a specific mechanism for implementing that strategic vision, and to identify a means by which they can be held accountable for achieving that vision. This paper has identified a path for development of a strategic vision, a new approach to technology and then product development efficiently to achieve that vision, and an approach to monitor RDT\&E to track the success of achieving the capabilities envisaged in that strategic plan. Notably, the recommendations have also included specific mechanisms for achieving significantly earlier limited introductions/demonstrations of new and innovative technologyenabled capabilities to the fleet/force and, through this, for gaining warfighter input into the technology development process as a means of solidifying requirements and specifications prior to initiation of BA-5 or BA-7 product development efforts. The lack of this latter element has been cited repeatedly as the major source of cost overruns and schedule slippages occurring in too many of our Major Development Acquisition Programs. 
It finally is worth noting comments from the Secretary of Defense at a late October 2013 standup at the Pentagon where he articulated his six priorities for the Department of Defense:

1. Institutional Reform - As it relates to the sequestration marks DOD will absorb over the next 10 years

2. Developing the Proper Force Construct - As we disengage from Iraq and Afghanistan and address new fiscal realities

3. Managing Readiness.

4. Capturing Emerging Capabilities - Specifically space, cyber, ISR, and SOF

5. Achieving Balance

6. Arresting and Managing the Growth in Health Care Costs

It has been said that when it looks like you cannot get there from here, you can either give up, or you have to try some entirely different approaches to what you have been doing. The Secretary's first priority above is a demand that DOD re-form itself and its processes, as needed to succeed, even in a challenging environment. This paper provides eight recommendations that provide exactly for:

(1) Institutional Reform - The paper recommends a fundamental re-forming of the DON RDT\&E portfolio with a Strategic Plan developed by senior leadership; with program decisions for major parts of the technology development portfolio (i.e. the BA-3 FNC and BA-4) at the DON rather than warfighter-community level; with early experiments with and demonstrations of new and of innovative/disruptive technology-driven capabilities to get warfighter buy-in on requirements, specifications, and capabilities before initiation of an MDAP, and also then providing a clear demonstration of what the technology can actually contribute to the warfighter mission; with use of early experiments and demonstrations (not managed by the product development community) to resolve technology risks, prior to MDAP initiation, and to reduce cost and schedule overruns; and with use of early prototypes as a mechanism for enabling speed to fleet/force. RDT\&E cannot be looked upon, as it appears to be now, as a support mechanism for or as a tail underneath of procurement, but rather should be looked upon by DON leadership as the means for leading the development of the capabilities required for the dominant success of the Navy and Marine Corps of the future.

(2) Developing the Proper Force Construct - The re-forming of RDT\&E to be more responsive to senior leadership strategic direction will drive the RDT\&E pipeline to delivering technology-enabled capabilities that align with leadership's vision for the proper force construct and will do so with early feedback to leadership from the fleet and force enabled by early experimentation and prototype demonstrations.

(4) Capture Emerging Capabilities - Developing a robust RDT\&E plan with incentives for risk taking in technology development (and particularly in S\&T) and with provision for early experiments and operational demonstrations to promote S\&T development of and fleet/force early buy-in on innovative technologies. 
This page intentionally left blank. 


\section{References}

1. 'Best Practices: Stronger Practices Needed to Improve DOD Technology Transition Processes,’’ Government Accountability Office, GAO-06-883, Sep 2006.

2. 'Non-Acquisition Programs,'” Naval Audit Service, Audit Report N2002-0012, 23 Nov 2001.

3. 'Non-Acquisition Programs,'” Naval Audit Service, Audit Report N2012-0038, 26 Apr 2012.

4. ''Defense Technology Development: Technology Transition Programs Support Military Users, but Opportunities Exist to Improve Measurement of Outcomes,' Government Accountability Office, GAO-13-286, Mar 2013.

5. 'Navy Budget Activity 4 (BA-4, Advanced Component Development and Prototypes),' Naval Research Advisory Committee, (draft) Oct 2011.

6. ' 'Getting to Best : Reforming the Defense Acquisition Enterprise,' Business Executives for National Security, Jul 2009.

7. ''Evaluation of U.S. Air Force Preacquisition Technology Development, " Air Force Studies Board - National Research Council, The National Academies Press, 2011.

8. 'Performance of the Defense Acquisition System, 2013 Annual Report,' Office of the Under Secretary of Defense, Acquisition, Technology and Logistics, 2013.

9. “'Naval S\&T Strategic Plan,' Department of the Navy - Office of Naval Research, 1 Sep 2011.

10. '’Defense Acquisitions: DOD's Research and Development Budget Requests to Congress Do Not Provide Consistent, Complete, and Clear Information,'’ Government Accountability Office, GAO-07-1058, Sep 2007.

11. 'Naval Power 21 ... A Naval Vision,’’ Department of the Navy, Oct 2002.

12. ' 'Sea Power 21,’’ Admiral Vern Clark USN, U.S. Navy Proceedings, Oct 2002.

13. '’Marine Corps Strategy 21,’’ General J.I. Jones USMC, HQ USMC, 3 Nov 2000.

14. Speech and Comments, Hon. Ray Mabus, Secretary of the Navy, at National Defense University, 11 Sep 2013.

15. Speech and Comments, Hon. Frank Kendall, at COMDEF 13 (held at the National Press Club), 4 Sep 2013.

16. "Charter for the Naval Research, Development, Test and Evaluation Corporate Board," Department of the Navy, 19 Mar 2013.

17. "Financial Management Regulation,” DOD 7000.14-R Volume 2B, Chapter 5, revised Sep 2012.

18. Public Law 111-84, Section 219, 28 Oct 2009. 


\section{Appendix A: BA1-7 Definitions (from REF 17)}

Budget Activity 1, Basic Research. Basic research is systematic study directed toward greater knowledge or understanding of the fundamental aspects of phenomena and of observable facts without specific applications towards processes or products in mind. It includes all scientific study and experimentation directed toward increasing fundamental knowledge and understanding in those fields of the physical, engineering, environmental, and life sciences related to long-term national security needs. It is farsighted high payoff research that provides the basis for technological progress. Basic research may lead to: (a) subsequent applied research and advanced technology developments in Defense-related technologies, and (b) new and improved military functional capabilities in areas such as communications, detection, tracking, surveillance, propulsion, mobility, guidance and control, navigation, energy conversion, materials and structures, and personnel support. Programs in this category involve pre-Milestone A efforts.

Budget Activity 2, Applied Research. Applied research is systematic study to understand the means to meet a recognized and specific need. It is a systematic expansion and application of knowledge to develop useful materials, devices, and systems or methods. It may be oriented, ultimately, toward the design, development, and improvement of prototypes and new processes to meet general mission area requirements. Applied research may translate promising basic research into solutions for broadly defined military needs, short of system development. This type of effort may vary from systematic mission-directed research beyond that in Budget Activity 1 to sophisticated breadboard hardware, study, programming and planning efforts that establish the initial feasibility and practicality of proposed solutions to technological challenges. It includes studies, investigations, and non-system specific technology efforts. The dominant characteristic is that applied research is directed toward general military needs with a view toward developing and evaluating the feasibility and practicality of proposed solutions and determining their parameters. Applied Research precedes system specific technology investigations or development. Program control of the Applied Research program element is normally exercised by general level of effort. Program elements in this category involve preMilestone B efforts, also known as concept and technology development phase tasks, such as concept exploration efforts and paper studies of alternative concepts for meeting a mission need.

Budget Activity 3, Advanced Technology Development (ATD). This budget activity includes development of subsystems and components and efforts to integrate subsystems and components into system prototypes for field experiments and/or tests in a simulated environment. ATD includes concept and technology demonstrations of components and subsystems or system models. The models may be form, fit, and function prototypes or scaled models that serve the same demonstration purpose. The results of this type of effort are proof of technological feasibility and assessment of subsystem and component operability and producibility, rather than the development of hardware for service use. Projects in this category have a direct relevance to identified military needs. ATD demonstrates the general military utility or cost reduction potential of technology when applied to different types of military equipment or techniques. Program elements in this category involve pre-Milestone B efforts, such as system concept demonstration, joint and Service-specific experiments or technology demonstrations and generally have technology readiness levels of 4, 5, or 6. Projects in this category do not necessarily lead to subsequent development or procurement phases, but should have the goal of moving out of science and technology (S\&T) and into the acquisition process within the future 
years defense program (FYDP). Upon successful completion of projects that have military utility, the technology should be available for transition.

Budget Activity 4, Advanced Component Development and Prototypes (ACD\&P). Efforts necessary to evaluate integrated technologies, representative modes, or prototype systems in a high-fidelity and realistic operating environment are funded in this budget activity. The ACD\&P phase includes system-specific efforts that help expedite technology transition from the laboratory to operational use. Emphasis is on proving component and subsystem maturity prior to integration in major and complex systems and may involve risk reduction initiatives. Program elements in this category involve efforts prior to Milestone B and are referred to as advanced component development activities and include technology demonstrations. Completion of technology readiness level 6 and 7 should be achieved for major programs. Program control is exercised at the program and project level. A logical progression of program phases and development and/or production funding must be evident in the FYDP.

Budget Activity 5, System Development and Demonstration (SDD). SDD programs have passed Milestone B approval and are conducting engineering and manufacturing development tasks aimed at meeting validated requirements prior to full-rate production. This budget activity is characterized by major line item projects and program control is exercised by review of individual programs and projects. Prototype performance is near or at planned operational system levels. Characteristics of this budget activity involve mature system development, integration and demonstration to support Milestone $\mathrm{C}$ decisions, and conducting live fire test and evaluation and initial operational test and evaluation of production representative articles. A logical progression of program phases and development and production funding must be evident in the FYDP consistent with the Department's full funding policy.

Budget Activity 6, RDT\&E Management Support. This budget activity includes research, development, test, and evaluation efforts and funds to sustain and/or modernize the installations or operations required for general research, development, test, and evaluation. Test ranges, military construction, maintenance support of laboratories, operation and maintenance of test aircraft and ships, and studies and analyses in support of the RDT\&E program are funded in this budget activity. Costs of laboratory personnel, either in-house or contractor operated, would be assigned to appropriate projects or as a line item in the Basic Research, Applied Research, or ATD program areas, as appropriate. Military construction costs directly related to major development programs are included.

Budget Activity 7, Operational System Development. This budget activity includes development efforts to upgrade systems that have been fielded or have received approval for fullrate production and anticipate production funding in the current or subsequent fiscal year. All items are major line item projects that appear as RDT\&E Costs of Weapon System Elements in other programs. Program control is exercised by review of individual projects. Programs in this category involve systems that have received Milestone $\mathrm{C}$ approval. A logical progression of program phases and development and production funding must be evident in the FYDP, consistent with the Department's funding policy. 


\section{Appendix B: Technology Readiness Levels (TRL)}

\section{TRL Description}

1. Basic principles observed and reported. Lowest level of technology readiness. Scientific research begins to be translated into applied research and development. Examples might include paper studies of a technology's basic properties.

2. Technology concept and/or application formulated. Invention begins. Once basic principles are observed, practical applications can be invented. Applications are speculative and there may be no proof or detailed analysis to support the assumption. Examples are still limited to analytic studies.

3. Analytical and experimental critical function and/or characteristic proof of concept. Active research and development is initiated. This includes analytical studies and laboratory studies to physically validate analytical predictions of separate elements of the technology. Examples include components that are not yet integrated or representative.

4. Component and/or breadboard. Validation in laboratory environment. Basic technological components are integrated to establish that they will work together. This is relatively "low fidelity" compared to the eventual system. Examples include integration of "ad hoc" hardware in a laboratory.

5. Component and/or breadboard validation in a relevant environment. Fidelity of breadboard technology increases significantly. The basic technological components are integrated with reasonably realistic supporting elements so it can be tested in a simulated environment. Examples include "high fidelity" laboratory integration of components.

6. System/subsystem model or prototype demonstration in a relevant environment. Representative model or prototype system, which is well beyond that of TRL 5, is tested in a relevant environment. Represents a major step up in a technology's demonstrated readiness. Examples include testing a prototype in a high-fidelity laboratory environment or in simulated operational environment.

7. System prototype demonstration in an operational environment. Prototype near, or at, planned operational system. Represents a major step up from TRL 6, requiring demonstration of an actual system prototype in an operational environment such as in an aircraft, vehicle, or space. Examples include testing the prototype in a test bed aircraft.

8. Actual system completed and qualified through test and demonstration. Technology has been proven to work in its final form and under expected conditions. In almost all cases, this TRL represents the end of true system development. Examples include developmental test and evaluation of the system in its intended weapon system to determine if it meets design specifications.

9. Actual system proven through successful mission operations. Actual application of the technology in its final form and under mission conditions, such as those encountered in operational test and evaluation. Examples include using the system under operational mission conditions. 


\section{Appendix C: Acronyms}

ACAT

ACD\&P

ACMC

AE

AFSB

ASD R\&E

ASN

ASW

AT\&L

ATD

BA

BAA

BENS

C4ISR

CG

CMC

CNO

CNR

COCOM

CTE

DC

DCMC

DCNO

D\&I

DOD

DON

FFC

FNC

FOB

FY
Acquisition Category

Advance Component Development and Prototype

Assistant Commandant of the Marine Corps

Acquisition Enabler

Air Force Studies Board

Assistant Secretary of Defense (Research and Engineering)

Assistant Secretary of the Navy

Anti-submarine Warfare

Acquisition, Technology, and Logistics

Advanced Technology Development

Budget Activity

Broad Agency Announcement

Business Executives for National Security

Command, Control, Communications, Computers, Intelligence, Surveillance, and Reconnaissance

Commanding General

Commandant of the Marine Corps

Chief of Naval Operations

Chief of Naval Research

Combatant Command

Critical Technology Element

Deputy Commander

Deputy Commandant of the Marine Corps

Deputy Chief of Naval Operations

Discovery and Invention

Department of Defense

Department of the Navy

Fleet / Forces Command

Future Naval Capability

Flag Oversight Board

Fiscal Year 


\begin{tabular}{|c|c|}
\hline FYDP & Future Years Defense Program \\
\hline GAO & Government Accountability Office \\
\hline HQMC & Marine Corps Headquarters Staff \\
\hline INP & Innovative Naval Prototype \\
\hline IOT\&E & Initial Operational Test and Evaluation \\
\hline IPT & Integrated Product Team \\
\hline LFT\&E & Live-Fire Test and Evaluation \\
\hline LRIP & Low-Rate Initial Production \\
\hline ManTech & Manufacturing Technology \\
\hline MARFORCOM & Marine Corps Forces Command \\
\hline MCCDC & Marine Corps Combat Development Command \\
\hline MCOTEA & Marine Corps Operational Test and Evaluation Activity \\
\hline MCWL & Marine Corps Warfighting Laboratory \\
\hline MDAP & Major Development Acquisition Program \\
\hline NAVAIR & Naval Air Systems Command \\
\hline NRAC & Naval Research Advisory Committee \\
\hline NRC & National Research Council \\
\hline NWDC & Navy Warfare Development Command \\
\hline ONR & Office of Naval Research \\
\hline OPEVAL & Operational Evaluation \\
\hline OPNAV & Navy Headquarters Staff \\
\hline OSD & Office of the Secretary of Defense \\
\hline OUSD & Office of the Under Secretary of Defense \\
\hline PB14 & President’s Budget for FY14 \\
\hline PEO & Program Executive Officer \\
\hline $\mathbf{P M}$ & Program Manager \\
\hline POR & Program of Record \\
\hline QR & Quick Reaction \\
\hline $\mathbf{R} \& \mathbf{D}$ & Research and Development \\
\hline RDA & Research, Development and Acquisition \\
\hline RDT\&E & Research, Technology, Test and Evaluation \\
\hline RTT & Rapid Technology Transition \\
\hline
\end{tabular}


SDD

S\&E

SES

S\&T

SOF

SYSCOM

$\mathbf{T}$

TECHEVAL

TIPS

TOA

TOB

TOG

TRA

TRL

TTA

USAF

UUNS

UNTL

UUV

$\mathrm{U} \& \mathrm{~W}$

VCNO

WC
System Design and Development

Science and Engineering

Senior Executive Service

Science and Technology

Special Operations Forces

Systems Command

Tactical Air Programs

Technical Evaluation

Technology Insertion to Produce Savings

Total Obligation Authority

Technology Oversight Board

Technology Oversight Group

Technology Readiness Assessment

Technology Readiness Level

Technology Transition Agreement

U.S. Air Force

Urgent Universal Needs Statement

Universal Naval Task List

Unmanned Underwater Vehicle

Unmanned Aviation and Strike Weapons

Vice Chief of Naval Operations

Warfare Center 


\section{Appendix D: Charter for the Naval RDT\&E Corporate Board CHARTER FOR \\ THE NAVAL RESEARCH, DEVELOPMENT, TEST AND EVALUATION CORPORATE BOARD}

1. PURPOSE. This Charter defines the mission, membership, organizational relationships and operating procedures of the Naval Research, Development, Test and Evaluation (RDT\&E) Corporate Board.

2. MISSION. The RDT\&E Corporate Board provides strategic oversight and monitoring of the Department of the Navy's (DON) RDT\&E investments and activities of RDT\&E (6.1-6.7) portfolios, programs, and priorities. The RDT\&E Corporate Board ensures the Department's RDT\&E budget and execution decisions support near- and long-term acquisition programs.

3. MEMBERSHIP

a) Chair. Under Secretary of the Navy.

b) Members:

1) Assistant Secretary of the Navy (Research, Development and Acquisition),

2) Vice Chief of Naval Operations, and

3) Assistant Commandant of the Marine Corps.

c) Co-executive secretaries:

1) Director, Innovation, Test and Evaluation and Technology Requirements (OPNAV N84) supports oversight activities associated with RDT\&E requirements and investment strategy.

2) Deputy Assistant Secretary of the Navy for RDT\&E (DASN (RDT\&E)) supports oversight activities associated with RDT\&E policy, infrastructure and workforce.

d) Advisor:

1) Deputy Under Secretary of the Navy for Plans, Policy, Oversight and Integration manages and coordinates strategic matters for the Under Secretary of the Navy, to include naval capabilities and alignment of Service investments with strategy and requirements.

4. RESPONSIBILITIES. The RDT\&E Corporate Board will establish and maintain a coordinated and comprehensive RDT\&E program to meet Naval goals and objectives by executing the following responsibilities:

a) Provide recommendations on strategic issues and policy changes to the Secretary of the Navy, the Chief of Naval Operations (CNO) and the Commandant of the Marine Corps (CMC), to ensure alignment between selected technologies and Naval needs.

b) Provide recommendations on strategic investments for Naval RDT\&E.

1) Oversight on Naval RDT\&E Strategic Plan,

2) Approval of the Naval S\&T Strategic Plan (a bi-annual process),

3) Approval for Innovative Naval Prototypes (INP - a bi-annual process), and 
4) Review of Future Naval Capabilities (PNC- an annual process managed by the threestar Technology Oversight Group).

a) Oversight of the various study groups and Flag Oversight Boards (FOB) examining technology application and RDT\&E strategy and investment.

b) Provide advice and assistance in developing policies for rapid technology transition by reviewing transition processes that move S\&T projects into acquisition RDT\&E programs of record, including Rapid Fielding Efforts (e.g., CNO Speed-to-Fleet).

5. OPERATING RELATIONSHIPS. The RDT\&E Corporate Board provides the SECNAV, CNO and CMC updates of key issues that require DON-wide solutions. Timing of updates will be such that decisions can inform the DON' s Programming, Planning, Budgeting and Execution process.

6. EFFECTIVE DATE. This charter is effective on the date of the last signature.

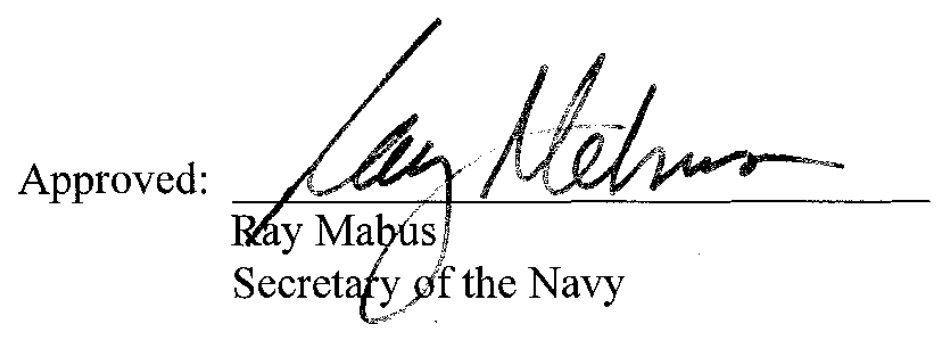

March 19, 2013 
This page intentionally left blank. 